Discussion Paper No. 03-09

\title{
Climate Policy Beyond Kyoto: Quo Vadis?
}

A Computable General Equilibrium Analysis Based on Expert Judgements

Christoph Böhringer and Andreas Löschel

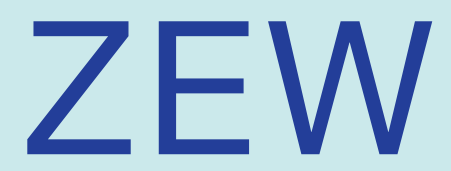

Zentrum für Europäische Wirtschaftsforschung GmbH

Centre for European

Economic Research 
Discussion Paper No. 03-09

\title{
Climate Policy Beyond Kyoto: Quo Vadis? \\ A Computable General Equilibrium Analysis Based on Expert Judgements
}

\author{
Christoph Böhringer and Andreas Löschel
}

Download this ZEW Discussion Paper from our ftp server:

\section{ftp://ftp.zew.de/pub/zew-docs/dp/dp0309.pdf}




\section{Nontechnical Summary}

Despite of the apparent failure of the Kyoto Protocol with respect to environmental effectiveness, it has established a broad international mechanism that might be able to provide a substantial emission reduction during a subsequent commitment period. This paper identifies policy-relevant post-Kyoto scenarios in a systematic way and quantifies the associated economic implications across major world regions.

We have combined two techniques for the purpose of our study. The cross-impact method is employed to survey experts and to determine the relative likelihood of different combinations of important elements for future climate policy: the level of global emission reduction from the business-as-usual, which countries participate and how, and how the burden of reduction is distributed among participants. The cross impact analysis delivers a small set of the most likely post-Kyoto policy scenarios. Their economic implications are then evaluated by means of a computable general equilibrium (CGE) model of global trade and energy use.

We find that post-Kyoto climate agreements are likely to achieve only small reductions in global emissions with abatement duties assigned to the industrialized world whereas developing countries are most likely to make not commitments to specific reduction targets. With respect to the allocation of abatement duties across the industrialized world, the sovereignty and ability-to-pay principle are the predominating equity rules. Comprehensive inter-regional trade in emissions ("where-flexibility") including developing countries that sell emission abatement to industrialized countries seems to be a conditio-sine-qua-non for all post-Kyoto policies. Global adjustment costs to achieve the main post-Kyoto target of a $10 \%$ reduction in world carbon emissions (compared to business-as-usual emissions in 2020) are very moderate due to comprehensive "where-flexibility". Substantial regional adjustment costs might arise for fuel-exporting regions due to strong terms-of-trade effects on fossil fuel markets. Interestingly, the economic implications of alternative future climate policy scenarios will remain robust for most world regions. This is due to the fact that cost implications of larger differences in abatement duties across key scenarios are substantially attenuated by robust terms-of-trade effects and low marginal abatement costs for global trade in emissions. 


\title{
Climate Policy Beyond Kyoto: Quo Vadis?
}

\author{
A Computable General Equilibrium Analysis \\ Based on Expert Judgements \\ Christoph Böhringer and Andreas Löschel \\ Centre for European Economic Research (ZEW) \\ P.O. Box 1034 43, D-68034 Mannheim, Germany
}

\begin{abstract}
Despite of the apparent failure of the Kyoto Protocol with respect to environmental effectiveness, it has established a broad international mechanism that might be able to provide a global reduction of greenhouse gas emissions during a second commitment period. In this paper we investigate the likely future of post-Kyoto policies. Our primary objective is to identify policy-relevant abatement scenarios and to quantify the associated economic implications across major world regions. Based on a cross-impact analysis we first evaluate an expert poll to select the most likely post-Kyoto climate policy scenarios. We then use a computable general equilibrium model to assess the economic implications of these key scenarios. We find that post-Kyoto agreements are likely to cover only small reductions in global greenhouse gas emissions with abatement duties predominantly assigned to the industrialized countries while developing countries do not make any commitments, but can sell emission abatement to the industrialized world. Equity rules to allocate abatement duties are mainly based on the sovereignty principle or ability-to-pay. Global adjustment costs arising from post-Kyoto policies are very moderate but fuel exporting countries are likely to face quite considerable costs because of adverse terms-of-trade effects on fossil fuel markets.
\end{abstract}

Keywords: climate policy, cross-impact analysis, computable general equilibrium modeling JEL: Q25, Q21, D58

Acknowledgements: We want to thank all respondents listed in the Appendix for their participation in the expert poll and their comments. John Reilly and Tim Hoffmann provided helpful suggestions. This research has been carried out under Study \#21 of the Energy Modeling Forum (EMF), Stanford University. Financial support by the European Commission (DG Environment) is gratefully acknowledged. Any remaining errors are our own. 


\section{Introduction}

Climate change due to anthropogenic greenhouse gas emissions has emerged as one of the most important issues facing the international community. Greenhouse gases - particularly fossil fuel-based carbon dioxide emissions - are accumulating in the atmosphere as a result of human activities, and the ongoing increase in greenhouse gas concentrations is expected to raise the global average temperature and cause other changes to the climate. Global consensus exists that climate change represents a significant potential threat requiring a considerable reduction of greenhouse gas emissions.

Given the public good character of the global atmosphere and the inherent free-riding incentives, the reduction of greenhouse gas emissions cannot be achieved without international cooperation which needs to be codified in international policy agreements. The Climate Change Convention adopted during the Rio Earth Summit in 1992 provides the institutional framework for such agreements. It was ratified by the vast majority of the world's states. Periodic meetings of the Parties to the Climate Change Convention - the socalled Conferences of Parties - are intended to promote and review global efforts to combat global warming. In 1997 the Third Conference of Parties adopted the Kyoto Protocol that requires industrialized countries to limit their emissions of greenhouse gases.

Initially, the Kyoto Protocol was intended to provide a substantial cutback in industrialized countries' business-as-usual emissions during the commitment period between 2008-2012 and, therefore, was celebrated as a breakthrough in international climate protection. Meanwhile, the withdrawal of the U.S. from the Protocol and full tradability of emission entitlements that was conceded to the former Eastern Bloc in excess of its anticipated future business-as-usual $(B a U)$ emissions (so-called hot air) implies that the current round of the Kyoto Protocol is likely to accomplish very little in terms of global emission reductions (see e.g. Böhringer, 2002; Böhringer and Vogt, 2003).

Despite of the apparent failure of the Kyoto Protocol with respect to environmental effectiveness, it established a broad international mechanism that might be able to provide substantial emission reductions during a subsequent commitment period. In this context, many analysts have thought about what climate policy beyond Kyoto might look like and made ad-hoc assumptions, for instance, that the Kyoto commitment will not change (e.g. Weyant, 1999).

Our primary objective is to identify policy-relevant post-Kyoto scenarios in a more systematic way and to quantify the associated economic implications across major world 
regions. We combined two techniques for the purpose of our study. In order to examine prospective future developments in climate protection and their interaction, we carried out a cross-impact analysis. Based on the cross-impact approach, we designed and carried out a poll on post-Kyoto abatement scenarios among 79 climate policy experts and then evaluated the results. Out of a large number of possible scenarios, the cross-impact analysis delivered only a few of the most likely scenarios for a second commitment period. We then evaluated the economic implications of these scenarios by means of a computable general equilibrium $(C G E)$ model of global trade and energy use. The main insights gathered from our analysis can be summarized as follows:

- Following the experts' judgements, post-Kyoto climate agreements are likely to achieve only small reductions in global emissions.

- Abatement duties to achieve the global emission reductions are assigned to the industrialized world, whereas developing countries are most likely to make not commitments to specific reduction targets.

- The sovereignty and ability-to-pay principle are the predominating equity rules for the allocation of abatement duties across the industrialized world. In the single key scenario that assigns abatement duties to all world regions, experts forecast the application of the sovereignty rule.

- Comprehensive inter-regional trade in emissions ("where-flexibility") including developing countries that sell emission abatements to industrialized countries seems to be a conditio-sine-qua-non for all post-Kyoto policies.

- The experts were undecided as to whether the U.S. will accept binding emission targets in a $2^{\text {nd }}$ commitment period or not.

- Global adjustment costs to achieve the main post-Kyoto target of a $10 \%$ reduction in world carbon emissions (compared to BaU emissions in 2020) are very moderate due to comprehensive "where-flexibility".

- Substantial regional adjustment costs might arise for fuel-exporting regions due to strong terms-of-trade effects on fossil fuel markets.

- The economic implications of alternative future climate policy scenarios will remain robust for most world regions. This is due to the fact that cost implications of larger differences in abatement duties across key scenarios are substantially attenuated by robust terms-of-trade effects and low marginal abatement costs for global trade in emissions. 
The remainder of this paper is as follows: section 2 presents the design and results of the cross-impact analysis on post-Kyoto emission reduction policies. Section 3 provides an overview of the CGE model that was applied to analyse the economic consequences of selected policy-relevant abatement scenarios and discusses the simulation results. Section 4 concludes this paper.

\section{Cross-impact analysis: identifying post-Kyoto policy scenarios}

Cross-impact analysis provides a systematic way to examine possible future developments and their interaction (Gordon and Hayward, 1968; Helmer, 1972; Enzer and Alter, 1978; Helmer, 1981). It collates expert judgements in order to construct a conceptual substitute for a nonexistent theory of how developments affect one another in a multidisciplinary context. A common procedure for cross-impact analysis consists of five steps (see Honton et al., 1984):

(i) Definition and structuring of the topic, (ii) identification of key scenario dimensions (events) and their possible states in the future, (iii) expert assessments of potential interactions between event pairs within a cross-impact matrix plus assignment of priori probabilities to each state, (iv) simulation of joint probabilities for interdependent events, i.e. the probabilities of future scenarios, and (v) selection of most likely scenarios.

We use the cross-impact approach to determine the relative likelihood of different combinations of future climate policy elements based on experts' judgements. Post-Kyoto climate policies comprise the level of global emission reduction from the business-as-usual emission level, which countries participate and how, and how the burden of reduction is distributed among the participants. For the sake of compactness, we restrict ourselves to a brief summary of the above steps used to determine key scenarios in a post-Kyoto commitment period. We employ a simple cross-impact analysis technique, which follows the BASICS (Batelle Scenario Inputs to Corporate Strategies) method (see e.g. Honton et al., 1984 and Huss, 1988) in many aspects. A detailed description of the cross-impact approach underlying our analysis can be downloaded from ftp://ftp.zew.de/pub/zewdocs/div/PostKyoto.pdf.

In our expert poll, we started with the assumption that the Kyoto Protocol boils down to $B a U$ : Industrialized countries (except for the U.S.) will continue to commit themselves to emission reductions within a post-Kyoto commitment and will be able to trade emission 
entitlements among each other. We then asked experts for their assessment of the crossrelationships between four key dimensions of a possible post-Kyoto scenario:

(A) Required global emission reduction (relative to $2020 \mathrm{BaU}$ level) suggests four global emission reduction targets with respect to the BaU emission level in 2020. Zero reduction (event $\mathrm{a}_{1}$ ) reflects a situation without any emission abatements, i.e. a $0 \%$ reduction. The remaining three reduction requirements are low (event $\mathrm{a}_{2}$ ), i.e. a $10 \%$ emission reduction, middle (event $\mathrm{a}_{3}$ ), i.e. a $20 \%$ emission reduction, and high (event $\mathrm{a}_{4}$ ), i.e. a $30 \%$ emission reduction. These reduction requirements are in line with alternative long-term stabilization targets of atmospheric $\mathrm{CO}_{2}$ concentrations as assessed in the IPCC Special Report on Emission Scenarios by the Intergovernmental Panel on Climate Change (Nakicenovic and Swart, 2000). More specifically, a 10\% reduction vis-à-vis the $2020 \mathrm{BaU}$ emission levels is consistent with a stabilization of atmospheric $\mathrm{CO}_{2}$ concentrations at $650 \mathrm{ppmv}$, a $20 \%$ emission reduction with 550 ppmv, and a 30\% emission reduction with 450 ppmv (Mori and Takahashi, 1998; Morita, 1999).

(B) US participation in the abatement coalition will be the case (event $\mathrm{b}_{1}$ : target) / will not be the case. If the US is not member of the abatement coalition, it will either be granted the permission to sell project-based emission reductions (event $\mathrm{b}_{2}$ : no target), or not (event $\mathrm{b}_{3}$ : out).

(C) Participation of developing countries in the abatement coalition will be the case (event $\mathrm{c}_{1}$ : target) / will not be the case. If developing countries are no members of the abatement coalition, they will either be granted the permission to sell project-based emission reductions (event $c_{2}$ : no target), or not (event $c_{3}$ : out).

Equity considerations are a central issue in the policy debate on future abatement commitments. There is no generally accepted definition of the term equity. Equity principles refer to normative concepts of distributive justice or fairness. Ringius et al. (1999) distinguishes between five equity principles: An egalitarian principle, i.e. people have equal rights to use the atmosphere; a horizontal principle, i.e. actors under similar (economic) conditions have similar emission rights and burden sharing responsibilities; a vertical principle, i.e. the greater the capacity to act or the ability to pay the greater the (economic) burden; the polluter-pays principle, i.e. the greater the contribution to the problem the greater the burden; and the sovereignty principle, i.e. current emissions constitute a status quo right now. Our final dimension of post-Kyoto policies reflects such equity rules: 
(D) Equity principles provide four alternative burden-sharing rules governing the allocation of overall abatement duties across members of the abatement coalition: egalitarian, abilityto-pay, polluter-pays, and sovereignty rules. Under the egalitarian rule (event $\mathrm{d}_{1}$ ) emission entitlements will be shared in equal-per-capita proportions based on population figures for 2010. With ability-to-pay (event $\mathrm{d}_{2}$ ) the absolute reduction requirement between 2010 and 2020 will be shared by regions according to their shares in GDP for the year 2010. Under the polluter-pays principle (event $\mathrm{d}_{3}$ ) the absolute reduction requirement between 2010 and 2020 will be shared by regions according to their shares in emissions for the year 2010. Under the sovereignty rule (event $\mathrm{d}_{4}$ ), emission entitlements will be shared in proportion to the emissions in 2010.

The scenario dimensions and associated events define the structure of the cross-impact matrix as given in Table 1.

Table 1: $\quad$ Cross-impact matrix for post-Kyoto commitments (mean values)

\begin{tabular}{|c|c|c|c|c|c|c|c|c|c|c|c|c|c|c|}
\hline & \multicolumn{3}{|c|}{ A: Target } & \multicolumn{2}{|c|}{ B: US } & \multicolumn{3}{|c|}{$\mathrm{C}: \mathrm{DC}$} & \multicolumn{4}{|c|}{ D: Equity } & \multirow[t]{2}{*}{ Prob. } \\
\hline & & $\mathrm{a}_{1} \quad \mathrm{a}_{2}$ & $a_{3}$ & $a_{4}$ & $b_{1} b_{2}$ & $\mathrm{~b}_{3}$ & $\mathrm{c}_{1}$ & $\mathrm{C}_{2}$ & $c_{3}$ & $\mathrm{~d}_{1}$ & $\mathrm{~d}_{2}$ & $\mathrm{~d}_{3}$ & $\mathrm{~d}_{4}$ & \\
\hline \multirow{4}{*}{$\begin{array}{l}\text { A: Required } \\
\text { emission } \\
\text { reduction } \\
\text { wrt } 2020\end{array}$} & $a_{1}$ Zero $(0 \%)$ & $X \quad X$ & $X$ & $\mathrm{X}$ & $2^{*} 0$ & -1 & 1 & 0 & 0 & 0 & 1 & 0 & 0 & 0.18 \\
\hline & $a_{2}$ Low $(10 \%)$ & $X \quad X$ & $X$ & $X$ & 0 & 0 & 0 & 1 & 0 & 0 & 1 & 0 & 0 & 0.43 \\
\hline & $a_{3}$ Middle $(20 \%)$ & $X \quad X$ & $X$ & $X$ & -1 & 1 & 0 & 1 & 0 & -1 & 0 & 0 & 0 & 0.27 \\
\hline & $a_{4} \operatorname{High}(30 \%)$ & $X$ & $X$ & $X$ & -2 & 1 & -1 & 1 & 0 & -1 & 0 & 0 & 0 & 0.12 \\
\hline \multirow{3}{*}{$\begin{array}{l}\text { B: US partici- } \\
\text { pation }\end{array}$} & $\mathrm{b}_{1}$ Target & 1 & 0 & -1 & $X \quad X$ & $\mathrm{X}$ & 2 & 0 & -1 & -2 & 0 & 0 & 2 & 0.49 \\
\hline & $\mathrm{b}_{2}$ No target & 0 & 0 & 0 & $\mathrm{X} X$ & $X$ & -1 & 1 & 1 & 0 & 1 & 0 & 0 & 0.26 \\
\hline & $b_{3}$ Out & 0 & -1 & -1 & $X$ & $X$ & -2 & 0 & 2 & 0 & 0 & 0 & -1 & 0.25 \\
\hline \multirow{3}{*}{$\begin{array}{l}\text { C: Develop- } \\
\text { ing countries' } \\
\text { participation }\end{array}$} & $\mathrm{c}_{1}$ Target & 0 & 1 & 1 & 0 & -2 & $X$ & $X$ & $X$ & 1 & 1 & 0 & -1 & 0.36 \\
\hline & $c_{2}$ No target & 0 & 0 & 0 & -1 & 0 & $X$ & $\mathrm{X}$ & $X$ & -1 & 0 & 0 & 0 & 0.44 \\
\hline & $c_{3}$ Out & 1 & -1 & -2 & -2 & 2 & $X$ & $X$ & $X$ & -1 & 0 & 0 & 0 & 0.20 \\
\hline \multirow{4}{*}{$\begin{array}{l}\text { D: Equity } \\
\text { principle }\end{array}$} & $\mathrm{d}_{1}$ Egalitarian & 1 & -1 & -2 & -2 & 2 & 2 & 0 & -2 & $X$ & $X$ & $X$ & & 0.12 \\
\hline & $\mathrm{d}_{2}$ Ability-to-pay & 1 & 0 & -1 & -1 & 0 & 1 & 0 & -1 & $\mathrm{X}$ & $X$ & $X$ & $\mathrm{X}$ & 0.30 \\
\hline & $\mathrm{d}_{3}$ Polluter-pays & 1 & 0 & -1 & -1 & 0 & 0 & 0 & -1 & $\mathrm{X}$ & $X$ & $X$ & $\mathrm{X}$ & 0.29 \\
\hline & $\mathrm{d}_{4}$ Sovereignty & 0 & 0 & -1 & 2 & -1 & -1 & 0 & 1 & $\mathrm{X}$ & $X$ & $X$ & $\mathrm{X}$ & 0.30 \\
\hline \multicolumn{2}{|l|}{$\begin{array}{ll}\text { Scale: } & -3 \\
& -2 \\
& -1\end{array}$} & & & & $\begin{array}{l}1 \\
2 \\
3\end{array}$ & & & & & & & & & \\
\hline
\end{tabular}

Clearly, this structure imposes strong constraints on what a Post-Kyoto policy might look like and thus limits the universe of possible policy combinations. The experts had to 
estimate how the occurrence of each event would impact the probability that all the other events would occur. To quantify these cross impacts between event-pairs, experts were to choose a number from (-3) "reduces probability of occurrence significantly" to (+3) "increases probability of occurrence significantly". The events in the rows represent the (direct) impact source for the events in the columns of the matrix (impact sinks). At each matrix intersection, the experts had to answer the following question: If an event in the row were to occur, how would it affect the probability that the event in the column will occur? For example, the value " -2 " in the matrix cell at the intersection of row $d_{1}$ and column $b_{1}$ suggests that the adoption of the egalitarian principle (occurrence of event $\mathrm{d}_{1}$ ) "reduces" the probability of US participation (occurrence of event $b_{1}$ ). In addition, the experts entered a priori probabilities of each future state in the last column of the matrix.

Table 1 summarizes the average cross impacts and probabilities collected from 79 climate policy experts (see Appendix for the list of participants). The experts reached consensus on several events. The experts unanimously agree that there will be some global emission reduction vis-a-vis the $B a U$ emission level in 2020, however, almost half of them forecasted that this would only be a minor $10 \%$ reduction. It seems almost certain to the experts that a future post-Kyoto policy will be based on unrestricted "where-flexibility", i.e. all regions - independent of explicit reduction commitments or not - can trade in emissions. Obviously, the egalitarian principle underlying the allocation rule for abatement duties (or likewise emission entitlements) is by no means the solution, but on the other hand there is no clear consensus on the acceptability of the remaining equity principles.

The experts' assessment of the potential interactions between each event-pair in the cross-impact matrix suggests that low reduction targets will increase the probability of U.S. commitments. More stringent reduction requirement, however, will reduce the probability that the U.S. will adopt explicit reduction targets; in this case it will be more likely that the U.S. will not be allowed to participate in an international emissions trading regime. This correlation is not found with respect to the developing countries' decisions to participate in the agreement. In addition, there are strong correlations between U.S. participation and the participation of the developing countries. Participation of the U.S. will increase the probability of developing countries' participation and vice versa.

Given the experts' judgements on cross impacts, it is possible to let events "happen" randomly in accordance with their estimated probability and then to trace out a distinct, plausible, and consistent future (see e.g. Honton et al., 1984 and Huss, 1988 for details). Thus, the cross-impact technique can be used as an experimental tool to simulate the process of 
eventoccurrence and to evaluate the average likelihood of occurrence of each event in a set of inter-related events. It is then possible to simulate the joint probabilities for interdependent events, i.e. the scenario probabilities, and to adjust the $a$ priori probabilities accordingly in the last column of the matrix.

Based on the experts' judgements, our heuristic simulations (in total 7800 runs) generated 121 scenarios out of $144(=4 \cdot 3 \cdot 3 \cdot 4)$ possible scenarios, out of which we selected only scenarios with a frequency of occurrence of more than $3 \%$ for further investigation based on the CGE model. Table 2 provides a summary of these (eight) most likely future commitment scenarios that cover about $40 \%$ of the generated scenarios in our simulations.

Table 2: $\quad$ Most likely scenarios for post-Kyoto commitments

\begin{tabular}{llllcc}
\hline Scenario & Target & US part. & DC part. Equity rule & $\begin{array}{c}\text { Frequency } \\
\text { (absolute) }\end{array}$ & $\begin{array}{l}\text { Frequency } \\
\text { (relative) }\end{array}$ \\
\hline$S 1: \mathrm{a}_{2} \mathrm{~b}_{2} \mathrm{c}_{2} \mathrm{~d}_{4}$ & $10 \%$ & No target & No target Sovereignty & $8.0 \%$ & $20.0 \%$ \\
$S 2: \mathrm{a}_{2} \mathrm{~b}_{1} \mathrm{c}_{2} \mathrm{~d}_{4}$ & $10 \%$ & Target & No target Sovereignty & $6.5 \%$ & $16.3 \%$ \\
$S 3: \mathrm{a}_{2} \mathrm{~b}_{1} \mathrm{c}_{1} \mathrm{~d}_{2}$ & $10 \%$ & Target & Target Ability-to-pay & $6.0 \%$ & $15.0 \%$ \\
$S 4: \mathrm{a}_{2} \mathrm{~b}_{2} \mathrm{c}_{2} \mathrm{~d}_{3}$ & $10 \%$ & No target & No target Polluter pays & $5.3 \%$ & $13.3 \%$ \\
S5: $\mathrm{a}_{2} \mathrm{~b}_{1} \mathrm{c}_{1} \mathrm{~d}_{4}$ & $10 \%$ & Target & Target Sovereignty & $4.0 \%$ & $10.0 \%$ \\
S6: $\mathrm{a}_{2} \mathrm{~b}_{3} \mathrm{c}_{2} \mathrm{~d}_{2}$ & $10 \%$ & Out & No target Ability-to-pay & $3.7 \%$ & $9.3 \%$ \\
S7: $\mathrm{a}_{2} \mathrm{~b}_{2} \mathrm{c}_{2} \mathrm{~d}_{2}$ & $10 \%$ & No target & No target Ability-to-pay & $3.4 \%$ & $8.5 \%$ \\
S8: $\mathrm{a}_{2} \mathrm{~b}_{1} \mathrm{c}_{2} \mathrm{~d}_{2}$ & $10 \%$ & Target & No target Ability-to-pay & $3.0 \%$ & $7.5 \%$ \\
${ }^{*}{ }_{\text {with respect to all scenarios }}^{* *}$ with respect to selected key scenarios & &
\end{tabular}

All of our key scenarios are characterized by a $10 \%$ global reduction target. Except for one case (U.S. is out in scenario S6), the most likely scenarios are characterized by fullscale "where-flexibility". It is uncertain whether the U.S. will commit itself to binding targets or not, whereas the developing countries are most likely to make no commitments as was the case in the past while having the opportunity to sell domestic abatements. The predominating equity principles for sharing the abatement burden are sovereignty and ability-to-pay principle. 


\section{Computable general equilibrium analysis: evaluating policy impacts}

To quantify the compliance costs to future greenhouse gas emission reduction commitments, we employ a well-established multi-sector, multi-region CGE model of global trade and energy use (see e.g. Böhringer, 2002 or Böhringer and Rutherford, 2002). Due to the microconsistent comprehensive representation of market interactions, CGE models have become the standard tool for studying the economy-wide impacts of policy interference on resource allocations and the associated implications for the incomes of economic agents (see e.g. Conrad, 2001).

Table 3 summarizes the regional and sectoral aggregation of the model. The regional aggregation includes industrialized and developing regions that are central to the international climate policy debate.

\section{Table 3: $\quad$ Model dimensions}

\begin{tabular}{|c|c|c|c|c|}
\hline \multicolumn{2}{|c|}{ Countries and regions } & \multicolumn{3}{|c|}{ Production sectors } \\
\hline \multicolumn{2}{|c|}{ Industrialized } & Ener\& & & \\
\hline AUN & Australia and New Zealand & $\mathrm{COL}$ & Coal & \\
\hline CAN & Canada & GAS & Natural gas & \\
\hline EUR & Europe (incl. Eastern Europe) & CRU & Crude oil & \\
\hline FSU & Former Soviet Union & OIL & Refined oil products & Fossil fuels \\
\hline JPN & Japan & ELE & Electricity & \\
\hline USA & United States & \multicolumn{3}{|c|}{ Non-Energy } \\
\hline \multicolumn{2}{|c|}{ Developing } & EIS & \multirow{2}{*}{\multicolumn{2}{|c|}{$\begin{array}{l}\text { Energy-intensive sectors } \\
\text { Other manufactures \& services }\end{array}$}} \\
\hline ASI & Rest of Asia & ROI & & \\
\hline $\mathrm{CHN}$ & China & & & \\
\hline IND & India & & & \\
\hline MPC & Mexico and OPEC & & & \\
\hline MSA & Middle and South America & & & \\
\hline AFR & Africa & & & \\
\hline
\end{tabular}

To account for different emission intensities and substitution possibilities across energy goods, the model identifies five primary and secondary energy carriers. At the nonenergy production level, energy-intensive sectors are distinguished from the rest of the economy. As is customary in applied general equilibrium analysis, the model is based on economic transactions in a particular benchmark year (1997 in our case). Benchmark data determine parameters of the functional forms from a given set of benchmark quantities, prices, and elasticities. With respect to benchmark quantities and prices, we employ the 
GTAP-EG database as described in Rutherford and Paltsev (2000). The magnitude and distribution of abatement costs associated with the implementation of the Kyoto emission constraints crucially depend on the $B a U$ projections for gross domestic product, fuel prices, energy efficiency improvements, etc. In our comparative static framework, we infer the $B a U$ economic structure of the model's regions for the year 2020 using projections of the International Energy Outlook (DOE, 2001) for growth in gross domestic product, fossil fuel production, and future energy prices. We incorporate autonomous energy efficiency improvement factors which scale energy demand functions to match the exogenous emission forecasts. In our policy simulations below we measure the economic and environmental consequences of abatement policies with respect to the $B a U$ situation in 2020.

For the sake of brevity, we we will not present a detailed description of basic model assumptions, the model algebra, and the model parameterization which can be downloaded from ftp://ftp.zew.de/pub/zew-docs/div/PostKyoto.pdf.

The cross-impact analysis of section 2 revealed important "rules" concerning the design of policy-relevant post-Kyoto strategies. First, the global reduction target is set at the lowest possible level. Second, in $75 \%$ of the policy-relevant scenarios developing countries do not commit themselves to binding targets. Third, adoption of abatement targets by the developing world seems only realistic if the whole industrialized world - including the U.S. commits to emission reduction targets, too. And fourth, more than $90 \%$ of the policy-relevant scenarios assume that there will be global trade in emissions; only one scenario (S6) is characterized by sub-global trading (exclusion of the U.S. from emissions trading).

The above rules reflect the simple proposition that prospects for a broader political agreement on post-Kyoto strategies will depend on their economic implications in terms of the magnitude and distribution of adjustment costs across regions: a low global target combined with unrestricted emissions trading will provide moderate overall adjustment costs. From the perspective of burden sharing, there is a strong tendency for industrialized countries to assume historical responsibility for the greenhouse gas problem while the developing countries remain uncommitted.

Our numerical CGE simulations do not only simply provide price tags to the various policy scenarios. We can verify to what extent the implicit reasoning of experts remains valid if we account for non-trivial economic adjustment mechanisms, e.g. spillover effects from international markets. Table 4 summarizes the results across our eight key scenarios (in descending order of occurrence probability). 
Table 4: $\quad$ Simulation results

\begin{tabular}{|c|c|c|c|c|c|c|c|c|}
\hline & \multicolumn{8}{|c|}{ Scenarios } \\
\hline & $\begin{array}{c}S 1 \\
\mathrm{a}_{2} \mathrm{~b}_{2} \mathrm{c}_{2} \mathrm{~d}_{4}\end{array}$ & $\begin{array}{c}S 2 \\
\mathrm{a}_{2} \mathrm{~b}_{1} \mathrm{c}_{2} \mathrm{~d}_{4}\end{array}$ & $\begin{array}{c}S 3 \\
\mathrm{a}_{2} \mathrm{~b}_{1} \mathrm{c}_{1} \mathrm{~d}_{2}\end{array}$ & $\begin{array}{c}S 4 \\
\mathrm{a}_{2} \mathrm{~b}_{2} \mathrm{c}_{2} \mathrm{~d}_{3}\end{array}$ & $\begin{array}{c}S 5 \\
\mathrm{a}_{2} \mathrm{~b}_{1} \mathrm{c}_{1} \mathrm{~d}_{4}\end{array}$ & $\begin{array}{c}S 6 \\
\mathrm{a}_{2} \mathrm{~b}_{3} \mathrm{c}_{2} \mathrm{~d}_{2}\end{array}$ & $\begin{array}{c}S 7 \\
\mathrm{a}_{2} \mathrm{~b}_{2} \mathrm{c}_{2} \mathrm{~d}_{2}\end{array}$ & $\begin{array}{c}S 8 \\
\mathrm{a}_{2} \mathrm{~b}_{1} \mathrm{c}_{2} \mathrm{~d}_{2} \\
\end{array}$ \\
\hline Reduction & $10 \%$ & $10 \%$ & $10 \%$ & $10 \%$ & $10 \%$ & $10 \%$ & $10 \%$ & $10 \%$ \\
\hline US part. & no target & target & target & no target & target & out & no target & target \\
\hline DC part. & no target & no target & target & no target & target & no target & no target & no target \\
\hline Equity rule & $\begin{array}{l}\text { sove- } \\
\text { reignty }\end{array}$ & $\begin{array}{l}\text { sove- } \\
\text { reignty }\end{array}$ & $\begin{array}{l}\text { ability-to- } \\
\text { pay }\end{array}$ & $\begin{array}{l}\text { polluter- } \\
\text { pays }\end{array}$ & $\begin{array}{l}\text { sove- } \\
\text { reignty }\end{array}$ & $\begin{array}{l}\text { ability-to- } \\
\text { pay }\end{array}$ & $\begin{array}{l}\text { ability-to- } \\
\text { pay }\end{array}$ & $\begin{array}{l}\text { ability-to- } \\
\text { pay }\end{array}$ \\
\hline Probability & $8.0 \%$ & $6.5 \%$ & $6.0 \%$ & $5.3 \%$ & $4.0 \%$ & $3.7 \%$ & $3.4 \%$ & $3.0 \%$ \\
\hline \multicolumn{9}{|c|}{ A. Emission reduction targets for key scenarios (in percent vs $B a U$ in 2020) } \\
\hline AUN & 32.2 & 18.5 & 10.6 & 33.0 & -1.3 & 23.2 & 23.2 & 13.9 \\
\hline CAN & 31.2 & 17.2 & 12.0 & 33.5 & -2.9 & 26.2 & 26.2 & 15.8 \\
\hline EUR & 30.8 & 16.8 & 19.5 & 33.7 & -3.4 & 42.7 & 42.7 & 25.7 \\
\hline FSU & 37.6 & 24.9 & 2.3 & 30.4 & 6.8 & 5.0 & 5.0 & 3.0 \\
\hline JPN & 29.8 & 15.5 & 30.4 & 34.2 & -4.9 & 66.5 & 66.5 & 40.0 \\
\hline USA & 0.0 & 19.9 & 14.5 & 0.0 & 0.6 & 0.0 & 0.0 & 19.1 \\
\hline AFR & 0.0 & 0.0 & 4.6 & 0.0 & 11.9 & 0.0 & 0.0 & 0.0 \\
\hline ASI & 0.0 & 0.0 & 4.3 & 0.0 & 17.1 & 0.0 & 0.0 & 0.0 \\
\hline $\mathrm{CHN}$ & 0.0 & 0.0 & 3.0 & 0.0 & 24.6 & 0.0 & 0.0 & 0.0 \\
\hline IND & 0.0 & 0.0 & 3.9 & 0.0 & 17.3 & 0.0 & 0.0 & 0.0 \\
\hline MPC & 0.0 & 0.0 & 7.2 & 0.0 & 16.7 & 0.0 & 0.0 & 0.0 \\
\hline MSA & 0.0 & 0.0 & 9.0 & 0.0 & 27.8 & 0.0 & 0.0 & 0.0 \\
\hline TOTAL & 10.0 & 10.0 & 10.0 & 10.0 & 10.0 & 10.0 & 10.0 & 10.0 \\
\hline $\mathrm{IC}^{*}$ & 19.4 & 19.4 & 14.8 & 19.4 & -0.1 & 19.4 & 19.4 & 19.4 \\
\hline $\mathrm{DC}^{* *}$ & 0.0 & 0.0 & 5.0 & 0.0 & 20.7 & 0.0 & 0.0 & 0.0 \\
\hline \multicolumn{9}{|c|}{ B. Consumption change (in percent vs $\mathrm{BaU}$ ) } \\
\hline AUN & -0.62 & -0.49 & -0.42 & -0.63 & -0.33 & -0.58 & -0.53 & -0.45 \\
\hline CAN & -0.50 & -0.35 & -0.31 & -0.52 & -0.18 & -0.38 & -0.44 & -0.33 \\
\hline EUR & -0.04 & 0.04 & 0.03 & -0.05 & 0.15 & -0.16 & -0.09 & 0.00 \\
\hline FSU & -1.81 & -1.28 & -0.42 & -1.51 & -0.59 & -0.52 & -0.52 & -0.44 \\
\hline JPN & 0.03 & 0.07 & 0.03 & 0.01 & 0.13 & -0.12 & -0.07 & 0.00 \\
\hline USA & 0.09 & -0.06 & -0.02 & 0.09 & 0.09 & 0.03 & 0.09 & -0.05 \\
\hline AFR & -0.44 & -0.44 & -0.50 & -0.44 & -0.59 & -0.34 & -0.44 & -0.44 \\
\hline ASI & 0.27 & 0.27 & 0.22 & 0.27 & 0.09 & 0.28 & 0.27 & 0.27 \\
\hline $\mathrm{CHN}$ & 0.42 & 0.41 & 0.30 & 0.42 & -0.51 & 0.64 & 0.42 & 0.41 \\
\hline IND & 0.21 & 0.21 & 0.13 & 0.21 & -0.17 & 0.23 & 0.21 & 0.21 \\
\hline MPC & -0.91 & -0.91 & -1.04 & -0.91 & -1.22 & -0.83 & -0.90 & -0.90 \\
\hline MSA & 0.03 & 0.04 & -0.03 & 0.03 & -0.17 & 0.04 & 0.03 & 0.04 \\
\hline TOTAL & -0.05 & -0.05 & -0.05 & -0.05 & -0.05 & -0.07 & -0.05 & -0.05 \\
\hline $\mathrm{IC}^{*}$ & -0.07 & -0.07 & -0.03 & -0.07 & 0.12 & -0.17 & -0.07 & -0.07 \\
\hline $\mathrm{DC}^{* *}$ & 0.01 & 0.01 & -0.11 & 0.01 & -0.50 & 0.20 & 0.01 & 0.01 \\
\hline
\end{tabular}

*industrialized countries ${ }^{* *}$ developing countries 
Table 4: continued

\begin{tabular}{|c|c|c|c|c|c|c|c|c|}
\hline & \multicolumn{8}{|c|}{ Scenarios } \\
\hline & S1 & $S 2$ & $S 3$ & S4 & S5 & S6 & $S 7$ & $S 8$ \\
\hline & $\mathrm{a}_{2} \mathrm{~b}_{2} \mathrm{c}_{2} \mathrm{~d}_{4}$ & $\mathrm{a}_{2} \mathrm{~b}_{1} \mathrm{c}_{2} \mathrm{~d}_{4}$ & $\mathrm{a}_{2} \mathrm{~b}_{1} \mathrm{c}_{1} \mathrm{~d}_{2}$ & $a_{2} b_{2} c_{2} d_{3}$ & $\mathrm{a}_{2} \mathrm{~b}_{1} \mathrm{c}_{1} \mathrm{~d}_{4}$ & $\mathrm{~A}_{2} \mathrm{~b}_{3} \mathrm{c}_{2} \mathrm{~d}_{2}$ & $a_{2} b_{2} c_{2} d_{2}$ & $a_{2} b_{1} c_{2} d_{2}$ \\
\hline Reduction & $10 \%$ & $10 \%$ & $10 \%$ & $10 \%$ & $10 \%$ & $10 \%$ & $10 \%$ & $10 \%$ \\
\hline US part. & no target & target & target & no target & target & out & no target & target \\
\hline DC part. & no target & no target & target & no target & target & No target & no target & no target \\
\hline Equity rule & $\begin{array}{l}\text { sove- } \\
\text { reignty }\end{array}$ & $\begin{array}{l}\text { sove- } \\
\text { reignty }\end{array}$ & $\begin{array}{l}\text { ability-to- } \\
\text { pay }\end{array}$ & $\begin{array}{l}\text { polluter- } \\
\text { pays }\end{array}$ & $\begin{array}{l}\text { sove- } \\
\text { reignty }\end{array}$ & $\begin{array}{l}\text { ability-to- } \\
\text { pay }\end{array}$ & $\begin{array}{l}\text { ability-to- } \\
\text { pay }\end{array}$ & $\begin{array}{c}\text { ability-to- } \\
\text { pay }\end{array}$ \\
\hline Probability & $8.0 \%$ & $6.5 \%$ & $6.0 \%$ & $5.3 \%$ & $4.0 \%$ & $3.7 \%$ & $3.4 \%$ & $3.0 \%$ \\
\hline \multicolumn{9}{|c|}{ C. Consumption change per capita (in USD ${ }_{97}$ ) } \\
\hline AUN & -56.3 & -43.8 & -37.5 & -56.3 & -28.1 & -50.0 & -46.9 & -40.6 \\
\hline CAN & -51.4 & -35.1 & -29.7 & -51.4 & -18.9 & -37.8 & -43.2 & -32.4 \\
\hline EUR & -3.2 & 3.7 & 2.7 & -4.6 & 13.6 & -14.3 & -8.3 & -0.2 \\
\hline FSU & -22.0 & -15.6 & -5.1 & -18.6 & -7.1 & -6.4 & -6.4 & -5.4 \\
\hline JPN & 5.5 & 13.4 & 5.5 & 3.1 & 25.2 & -23.6 & -14.2 & 0.8 \\
\hline USA & 14.8 & -9.8 & -2.5 & 14.8 & 14.8 & 4.3 & 14.8 & -8.0 \\
\hline AFR & -0.9 & -0.9 & -1.1 & -0.9 & -1.3 & -0.8 & -0.9 & -0.9 \\
\hline ASI & 7.5 & 7.5 & 6.3 & 7.5 & 2.5 & 8.2 & 7.5 & 7.5 \\
\hline $\mathrm{CHN}$ & 1.5 & 1.5 & 1.1 & 1.5 & -1.8 & 2.3 & 1.5 & 1.4 \\
\hline IND & 0.5 & 0.4 & 0.2 & 0.5 & -0.3 & 0.5 & 0.4 & 0.4 \\
\hline MPC & -6.0 & -6.0 & -6.8 & -6.0 & -8.0 & -5.4 & -5.9 & -5.9 \\
\hline MSA & 0.7 & 0.7 & -0.6 & 0.7 & -3.2 & 0.7 & 0.7 & 0.7 \\
\hline \multicolumn{9}{|c|}{ D. Marginal abatement costs (in USD 97 per ton of carbon) } \\
\hline & 27 & 27 & 27 & 27 & 27 & 34 & 27 & 27 \\
\hline \multicolumn{9}{|c|}{ E. Emission reduction (in percent vs $\mathrm{BaU}$ ) } \\
\hline AUN & 5.3 & 5.2 & 5.2 & 5.3 & 5.2 & 7.1 & 5.3 & 5.2 \\
\hline CAN & 5.1 & 5.1 & 5.1 & 5.1 & 5.1 & 7.3 & 5.1 & 5.1 \\
\hline EUR & 2.9 & 2.9 & 3.0 & 3.0 & 2.9 & 4.1 & 3.0 & 3.0 \\
\hline FSU & 6.1 & 6.0 & 5.8 & 6.0 & 5.8 & 7.3 & 5.8 & 5.8 \\
\hline JPN & 3.0 & 3.0 & 3.0 & 3.0 & 3.0 & 4.3 & 3.1 & 3.1 \\
\hline USA & 7.2 & 7.2 & 7.2 & 7.2 & 7.2 & -1.3 & 7.2 & 7.2 \\
\hline AFR & 6.5 & 6.5 & 6.5 & 6.5 & 6.5 & 8.5 & 6.5 & 6.5 \\
\hline ASI & 9.5 & 9.5 & 9.5 & 9.5 & 9.5 & 11.2 & 9.5 & 9.5 \\
\hline $\mathrm{CHN}$ & 27.3 & 27.3 & 27.3 & 27.3 & 27.4 & 30.9 & 27.3 & 27.3 \\
\hline IND & 12.4 & 12.4 & 12.4 & 12.4 & 12.4 & 14.7 & 12.4 & 12.4 \\
\hline MPC & 6.1 & 6.1 & 6.2 & 6.1 & 6.2 & 7.7 & 6.1 & 6.1 \\
\hline MSA & 4.5 & 4.5 & 4.5 & 4.5 & 4.5 & 5.9 & 4.5 & 4.5 \\
\hline TOTAL & 10.0 & 10.0 & 10.0 & 10.0 & 10.0 & 9.7 & 10.0 & 10.0 \\
\hline
\end{tabular}




\section{Emission reduction targets}

Table 4A. reports the (exogenous) emission reduction targets that apply to various countries under the different scenarios and in total amount to a $10 \%$ reduction of global emissions visà-vis the $B a U$. The targets are derived using the reference case projections of the International Energy Outlook for emissions, GDP and population in the years 2010 and 2020 (DOE, 2001).

Non-commitment of the developing regions imposes substantial reduction targets to the developing world in order to cope with the global reduction requirement since the developing world accounts for nearly half of the $B a U$ emissions in 2020. Whenever the U.S. remains uncommitted, too, the total abatement burden for the remaining industrialized countries increases further. In the latter case, application of the sovereignty principle (scenario S1) or the polluter-pays principle (scenario S4) leads to similar reduction targets of around $30 \%$ for non-U.S. industrialized regions while the ability-to-pay principle (scenario S7) provides substantially lower reduction targets for FSU and higher targets for EUR and, particularly, JPN. If we consider those scenarios where all industrialized countries commit themselves (scenarios $S 2, S 3, S 5, S 8$ ), the application of the sovereignty rule implies a substantially smaller dispersion of emission reduction targets across industrialized countries than the ability-to-pay principle, which, in turn, produces a much higher dispersion.

Commitment of developing countries under the ability-to-pay principle (scenario S3) lowers the aggregate reduction burden for the industrialized world from nearly $20 \%$ of its $B a U$ emissions to $15 \%$ while the developing world in aggregate has to cut back its emissions by $5 \%$. If developing countries accept a world-wide allocation of abatement duties according to the sovereignty principle (scenario S5), they will carry the total global abatement burden whereas industrialized countries will be entitled to maintain their $\mathrm{BaU}$ emissions (or even slightly more).

\section{Aggregate adjustment costs}

A $10 \%$ reduction of world carbon emissions can be achieved at moderate global consumption losses. The main reason is that unrestricted emission trading assures global efficiency in the sense that abatement will be undertaken where it is cheapest on the globe. Marginal abatement costs are equalized world-wide, thus reducing global adjustment costs substantially vis-à-vis a situation with restricted "where"-flexibility. Unrestricted "where"-flexibility applies to all scenarios except $S 6$ in which the U.S. remain uncommitted and are not allowed to engage in emissions trading with the rest of the world. Therefore, the latter scenario stands out for the highest global marginal and inframarginal abatement costs (emission leakage in this case is 
negligibly small - see the line entitled "Total" in Table 4E.) As to the remaining scenarios, partial equilibrium analysis would produce exactly the same results with respect to global costs of abatement, marginal abatement costs and the (cost-efficient) abatement by region. However, in the general equilibrium framework wealth transfers that are associated with alternative reduction targets across regions produce income effects. The latter explain small deviations in emission reductions across globally efficient scenarios (as visible for a few entries in Table 4E.).

A comparison of aggregate consumption changes between the industrialized countries (IC) and developing countries (DC) provides policy-relevant insights. Whenever the developing countries remain uncommitted, the aggregate impact associated with unilateral abatement duties of the industrialized countries remains negligible. More specifically, indirect spillover effects from changes in international prices and direct benefits from sales of emission rights to the industrialized world cancel from the aggregate developing world's perspective. The one exception is scenario $S 6$, in which the developing world - as a seller of emission rights - benefits from increased international emission prices due to the exclusion of the U.S. from international emissions trading.

When developing countries accept reduction targets (scenarios S3 and S5) they are in aggregate substantially worse off than the developed world, in particular for the case where abatement duties are allocated according to the sovereignty principle (scenario S5). In the latter scenario, the aggregate consumption loss for the developing world amounts to $0.5 \%$ whereas the developed world does even better than under business-as-usual conditions (note that this scenario after all holds a relative probability of $10 \%$ among our key policy scenarios): industrialized countries which are in part endowed with emission entitlements in excess of their $B a U$ emission levels profit from sales of their emission rights.

\section{Country-specific adjustment costs}

At the single-region level, the picture of the magnitude and distribution of adjustment costs changes quite a bit. There are three major determinants of adjustment costs associated with carbon emission constraints:

- the individual reduction target (the higher the reduction target, the larger will be - ceteris paribus - the region-specific adjustment costs),

- the ease of carbon substitution within production and consumption activities through fuel switching and energy savings, and 
- the trade characteristics driving the sign and magnitude of terms-of-trade effects. Termsof-trade effects work primarily through the decline of international fuel prices following the drop in energy demand under emission reduction policies: net fuel importers will perceive indirect benefits from cheaper energy imports, while net fuel exporters are negatively affected (see Böhringer and Rutherford, 2002 for a detailed discussion).

The striking insight from Table 4 is that the economic impacts for most regions remain robust across alternative future climate policy scenarios (The one outlier is scenario $S 5$ where developing countries have to shoulder the global reduction requirement.). This finding clearly indicates that the cost implications of larger differences in abatement duties across scenarios are substantially attenuated by robust terms-of-trade effects and low marginal abatement costs for global trade in emissions.

There are five regions that face larger negative impacts across all scenarios: AUN, CAN, and FSU among industrialized countries; MPC and AFR among developing countries. These five regions suffer from substantial consumption losses even for the case that they may dispose of excess emissions (AUN and CAN for scenario S5) or remain uncommitted to reduction targets (AFR and MPC for all scenarios except for S3 and S5). The reason are dominant adverse terms-of-trade effects for these fuel-exporting regions. Potential revenues from sales of emissions are by far too small to offset their terms-of-trade losses. In turn, regions which are fuel importers benefit from reduced international energy prices. All fuelimporting developing regions (ASI, CHN, IND, and MSA) increase consumption significantly beyond $\mathrm{BaU}$ levels whenever they do not commit themselves to emission reduction or only accept moderate reduction targets as imposed by the ability-to-pay principle (scenario S3). Consumption gains are most pronounced for IND and, particularly, CHN that can capitalize through emission trading on larger volumes of cheap domestic abatement options. The adoption of stringent emission reduction targets by developing countries in scenario $S 5$ imposes larger direct abatement costs on them that add up to terms-of-trade losses for fuel exporters and more than offset terms-of-trade gains for fuel importers. Except for ASI, the fuel-importing developing regions (CHN, IND, and MSA) then face substantial total adjustment costs which are quite in contrast to the outcome of the other policy scenarios. All developing regions except for MPC and AFR are not affected adversely as long as they do not commit themselves to emission reduction targets.

Among all regions, FSU will suffer the largest percentage consumption loss if developing countries do not accept explicit reduction targets and if abatement duties are allocated across the industrialized world based on the sovereignty- or polluter-pays-principle. 
The adjustment costs incurred by FSU will be substantially lower (rather independently from explicit targets to the developing countries) if the ability-to-pay-principle is applied as the burden-sharing rule.

In general, EUR and JPN benefit from reduced expenditure for fuel imports. Given moderate marginal abatement costs due to "where-flexibility", their terms-of-trade gains can more than offset direct abatement costs for substantial reduction targets (scenarios S1-S4, S8). Both countries are distinctly better off compared to $B a U$ when abatement duties are assigned across all world regions according to the sovereignty rule (scenario S5). Adoption of the ability-to-pay principle, when both the developing countries and the U.S. remain uncommitted, implies some adjustment costs to EUR and JPN because of the high specific reduction targets involved (scenario $S 7$ ). If, in addition, the U.S. are not allowed to participate in international emission trading (scenario S6), the costs to EUR and JPN will further increase due to higher marginal abatement costs.

The economic impacts on the U.S. are very moderate across all scenarios. The U.S. improve consumption vis-à-vis $B a U$ by around $0.1 \%$ for the cases of non-compliance (scenarios $S 1, S 4$, and $S 7$ - if the U.S. are kept out of emissions trading the gains drop to 0.03 $\%$ due to foregone revenues from emission sales). The same magnitude of gains is achieved if abatement duties are allocated across all countries based on the sovereignty principle (scenario S5) imposing only a negligible reduction target of $0.6 \%$ on the U.S. Whenever the U.S. assume explicit abatement duties, the implied adjustment costs remain very small. To summarize: from the U.S. climate policy perspective, compliance with a post-Kyoto commitment involving a global emission reduction of $10 \%$ and unrestricted "where"flexibility does not result in substantial costs even for the cases where developing countries do not accept initial emission constraints on their economies.

\section{Sensitivity analysis}

In order to evaluate the sensitivity of our central model results with respect to uncertainties in the elasticity space we have conducted 1000 Monte Carlo simulations. In each simulation, values for six elasticities (trade elasticities, energy demand elasticities and fossil fuel supply elasticities) that are key determinants for the economic adjustment costs associated with emission constraints were drawn from uniform probability distributions around the model central values (see Table C.4 in the download). Table 5 provides a statistical summary of results for the percentage changes in consumption relative to the $B a U$ levels in 2020. Across the eight key scenarios, we have listed the core (central case) values together with the median 
as well as the $10 \%$ quantile and $90 \%$ quantile. Although we observed some spread, all of our insights based on the central case general equilibrium estimates remain robust even when accounting for substantial uncertainty in the parameterization space.

Figures 2 and 3 visualize the dispersion of results for each region across the different scenarios. We used box-plots to mark the range between the $10 \%$ quantile and the $90 \%$ quantile. In addition, we have entered the median value as well as the core simulation result. The plots confirm the robustness of our findings with respect to major changes in the parameterization of elasticities.

The fuel-importing developing regions ASI, IND, and CHN that dispose of larger lowcost mitigation options fare distinctly better than under business-as-usual conditions. By contrast, the fuel-exporting developing regions AFR and MPC suffer from global emission abatement. There is one future climate policy that violates this uniform cost pattern, i.e. scenario S5 where the developing world takes over the global abatement duty imposing adjustments costs on (nearly) all developing regions. Among the industrialized regions, AUN, CAN, and FSU face substantial adjustment costs. In particular FSU is adversely affected when higher specific emission reduction duties cause larger direct abatement costs on top of its terms-of-trade losses on fossil fuel markets (scenarios $S 1, S 2$, and S4). EUR and JPN exhibit the very same pattern of consumption changes across all future climate policy scenarios. Their terms-of-trade gains on fossil fuel markets lower or more than offset even direct costs associated with their specific abatement duties. As to the U.S., adoption of explicit reduction targets only results in very moderate costs whereas in all other (noncommitment) cases the U.S. perform slightly better than under $B a U$.

Apart from elasticity values, the effects induced by future carbon policies depend on the $B a U$ economic structure of the model's regions. The results presented in Tables 4 and 5 are based on reference case projections of the International Energy Outlook. The latter provides additional baseline projections where the growth potential of the world economy is considered either from a more pessimistic perspective (low economic growth case projection) or a more optimistic angle (high economic growth case projection). Lower economic growth is linked to lower overall demand for fossil fuels and lower $B a U$ carbon emissions than in the reference case. The opposite applies for higher economic growth. In a "piecemeal" sensitivity analysis with respect to these alternative projections we found that the regional pattern of adjustment costs remains robust. The main reason is that regional economies are treated similarly within the different baseline projections inducing only small changes with respect to the implied emission reduction targets across the key scenarios. 


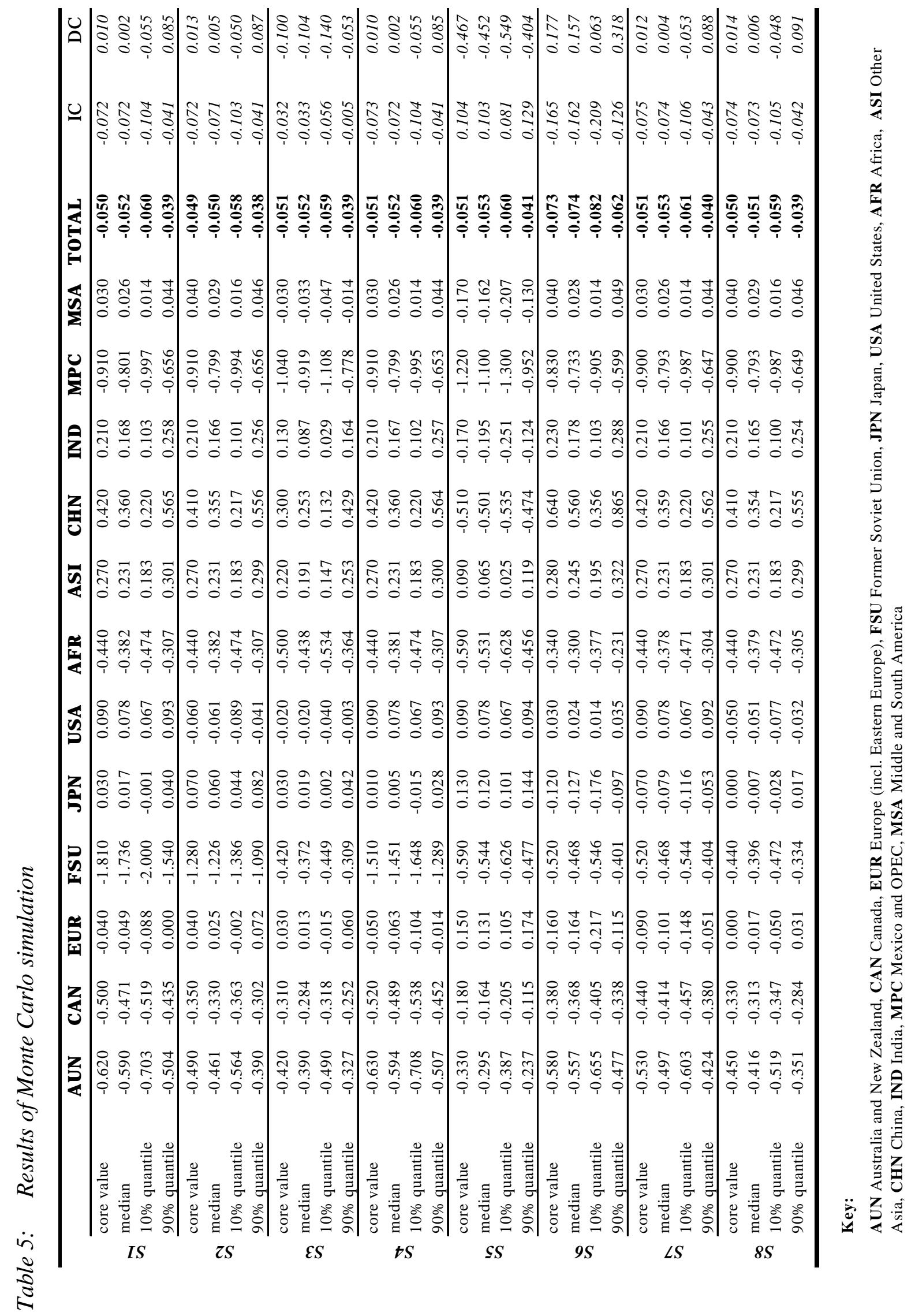


Figure 2: Consumption change (in percent vs BaU) - developing countries
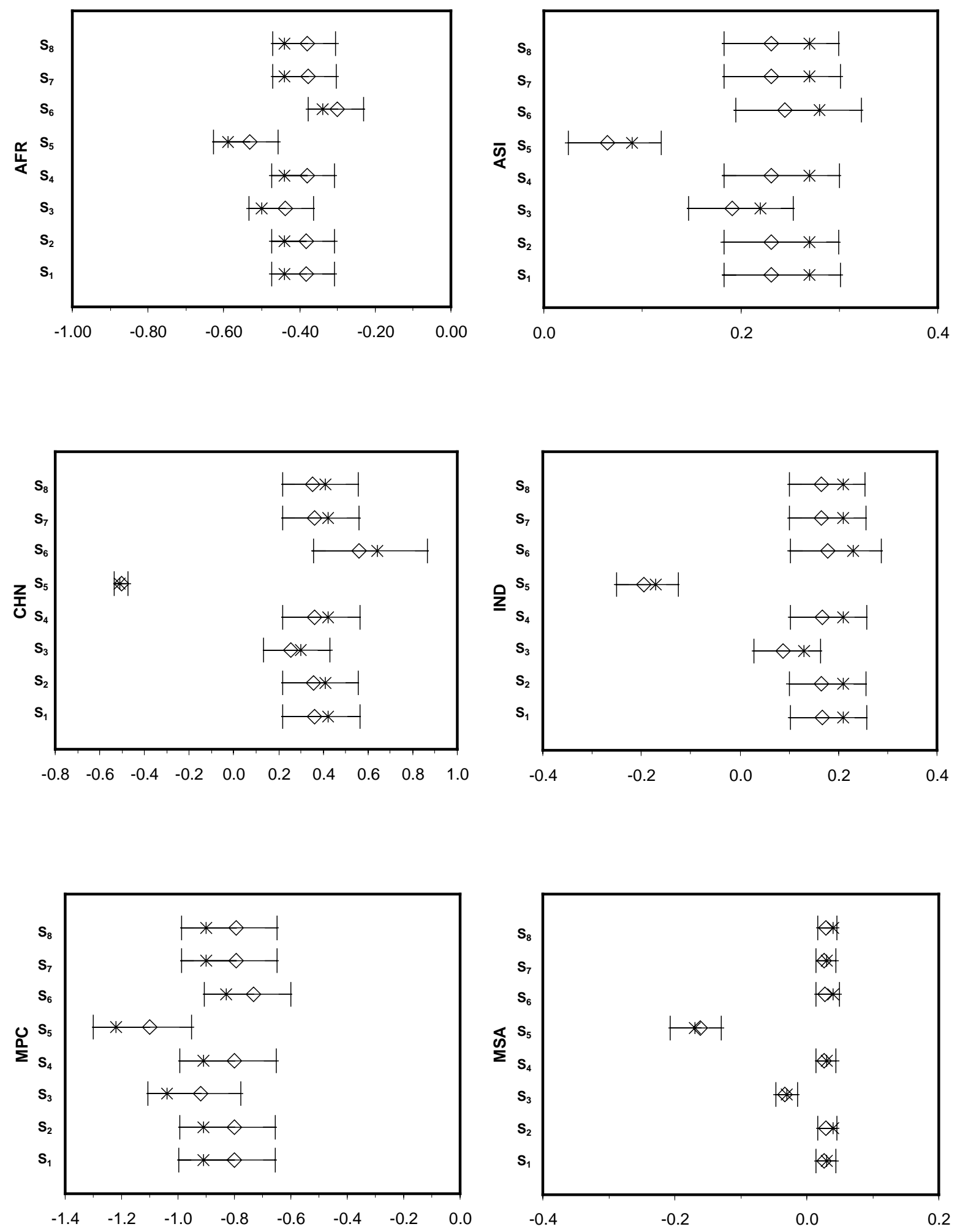

Key: I $10 \%$ and $90 \%$ quantile $\diamond$ Median $*$ Core value 
Figure 3: Consumption change (in percent vs BaU) - industrialized countries
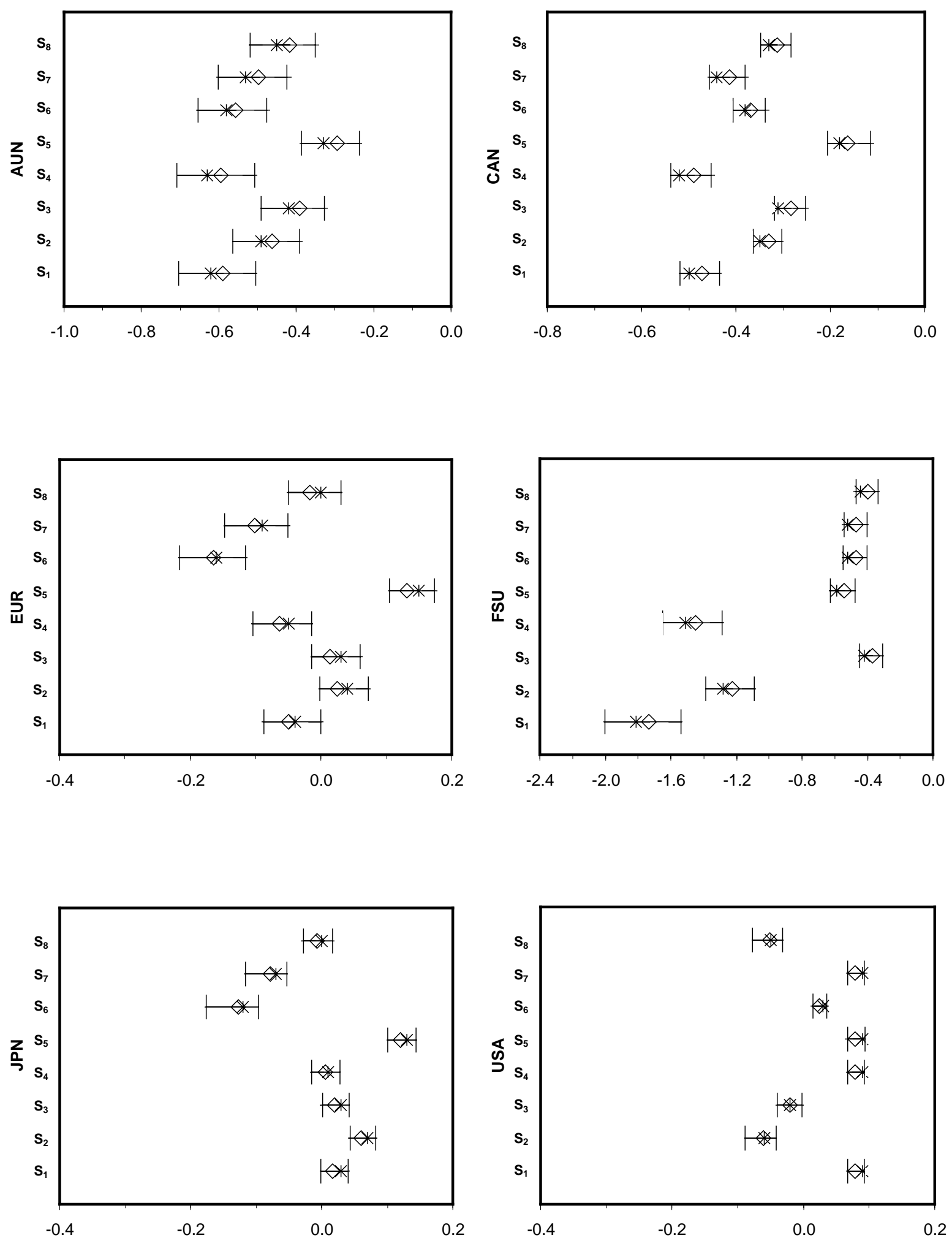

Key: I 10\% and 90\% quantile $\diamond$ Median $*$ Core value 


\section{Concluding remarks}

There is common scientific agreement that the mitigation of climate change requires a substantial reduction of anthropogenic greenhouse gas emissions. The Kyoto Protocol which has been widely eulogized as a first serious step towards slowing greenhouse warming requires industrialized regions to cap their emissions at specific target levels during the budget period of 2008-2012. Although the Protocol will apparently fail to provide a noticeable global emission reduction from $\mathrm{BaU}$ emission levels due to the U.S. withdrawal and trading of hot air, it has established a framework for subsequent climate change negotiations. In fact, the Protocol envisages that nations will negotiate on caps for future budget periods. From the perspective of international climate policy, there is obviously a strong interest in investigating the key elements of such post-Kyoto commitments.

This paper discusses the interdependencies of four factors that are crucial to the architecture of a future international agreement on emission abatement: the targeted global emission reduction, U.S. participation, inclusion of developing countries, and the allocation rule for abatement duties. After identifying the most likely characteristics of post-Kyoto scenarios, we furthermore quantified the associated economic impacts.

Our cross-impact analysis complemented by CGE simulations on future climate policies provides decision makers not only with an improved ability to anticipate likely occurrences and their economic consequences, but also to evaluate how their actions can change future outcomes. In our investigation we presumed that decision makers do not use such information for strategic behaviour. However, the insights presented in this paper may guide decision makers as they are working to influence policy determinants towards more desirable futures. In fact, decision makers may change our forecast in three different ways: first, by implementing policies to change the probability of one or more of the events making them more or less likely to occur; second, by implementing policies to change the impact of one or more of the events; and third, by adopting policies that create new events. The difference between the probabilistic forecast presented in this paper and the policy-impacted forecast, then, shows the benefit of implementing different climate policies. We plan to address such issues in future research. 


\section{References}

Böhringer, C. (2002), Climate Politics From Kyoto to Bonn: From Little to Nothing?, The Energy Journal, 23 (2), 51-71.

Böhringer, C. und T. F. Rutherford (2002), Carbon Abatement and International Spillovers, Environmental and Resource Economics 22(3), S. 391-417.

Böhringer, C. and C. Vogt (2003), Economic and Environmental Impacts of the Kyoto Protocol, in: Canadian Journal of Economics, forthcoming.

Conrad, K. (2001), Computable General Equilibrium Models in Environmental and Resource Economics, in: T. Tietenberg and H. Folmer (eds.): The International Yearbook of Environmental and Resource Economics 2002/2003, 66-114.

DOE (Department of Energy) (2001), International Energy Outlook, Washington, DC: Energy Information Administration.

Enzer, S. (1971), 'Delphi and Cross-Impact Techniques - An Effective Combination for Systematic Futures Analysis', Futures, 3, 48-61.

Enzer. S. and S. Alter (1978), 'Cross-Impact Analysis and Classical Probability - The Question of Consistency', Futures, 10, 227-239.

Gordon, T. J. and H. Hayward (1968), 'Initial Experiments with the Cross-Impact Matrix Method of Forecasting', Futures, 1 (2), 100-116.

Helmer, O. (1972), 'Cross-Impact Gaming', Futures, 4 (2), 149-167.

Helmer, O. (1981), 'Reassessing Cross-Impact Analysis', in: Futures, 13, 389-400.

Honton, E. J., G. S. Stacey and S. M. Millett (1984), 'Futures Scenarios: The BASICS Computational Method', Battelle Columbus Division, Economics and Policy Analysis, Occasional Paper 44.

Huss, W. R. (1988), ‘A Move Toward Scenario Analysis', International Journal of Forecasting, 4, 377-388.

Kolshus, H. H., J. Vevatne, A. Torvanger and K. Aunan (2001), Can the Clean Development Mechanism Attain both Cost-effectiveness and Sustainable Development Objectives?, CICERO Working Paper 2001:8.

Nakicenovic, N. and R. Swart (eds.) (2000), Emissions Scenarios, Special Report of the Intergovernmental Panel on Climate Change, Cambridge: Cambridge University Press. 
Mori, S. and M. Takahashi (1998), 'An Integrated Assessment model for New Energy Technologies and Food production - An Extension of the MARIA Model', International Journal of Global Energy Issues, 11 (1-4), 1-17.

Morita, T. (1999), Emission Scenario Database, Prepared for IPCC Special Report on Emission Scenarios convened by N. Nakicenovic, http://www-cger.nies.go.jp/cgere/db/ipcc.html.

Ringius, L., A. Torvanger, and A. Underdal (1999), Burden Differentiation: Fairness Principles and Proposals, Working Paper 1999:13, Oslo: CICERO.

Rutherford, T. F. and S. V. Paltsev (2000), GTAP-EG: Incorporating Energy Statistics into GTAP Format, University of Colorado Department of Economics.

Weyant, J. (ed.) (1999), 'The Costs of the Kyoto Protocol: A Multi-Model Evaluation', The Energy Journal, Special Issue. 


\section{Appendix: List of Poll Respondents}

Ahn, Y.-K., Ministry of Environment, Korea

Babiker, M., Arab Planning Institute, Kuwait (Sudanese)

Bahn, O., Paul Scherrer Institute (PSI), Switzerland (French)

Barbu, A.-D., University of Oldenburg, Germany (Romanian)

Barker, T., University of Cambridge, UK

Bernard, A., Ministry of Equipment, France

Bernheim, T., Federal Planning Bureau, Belgium

Bernstein, P., Charles River Associates, USA

Blok, K., ECOFYS Energy and Environment, The Netherlands

Bollen, J., Institute for Environmental Studies (IVM), The Netherlands

Bouille, D., Bariloche Foundation, Agentina

Chmelik, T., Ministry of the Environment, Czech Republic

Choi, J.-C., Ministry of Foreign Affairs and Trade, Korea

Criqui, P., Université Grenoble, France

de la Chesnaye, F., Environmental Protection Agency, USA

de Vries, B., Institute for Environmental Studies (IVM), The Netherlands

Estrada, M., Ministry of Environment and Natural Resources, Mexico

Eyckmans, J., K.U. Leuven, Belgium

Fahl, U., Institute of Energy Economics and the Rational Use of Energy (IER), Germany

Füeg, J.-C., Swiss Federal Office of Energy, Switzerland

Galeotti, M., University of Bergamo and Fondazione Eni Enrico Mattei (FEEM), Italy

Gerlagh, R., Institute for Environmental Studies (IVM), The Netherlands

Gordienko, T., Ministry of the Environment and Natural Resources, Ukraine

Graveland, C., Institute for Environmental Studies (IVM), The Netherlands

Gruenspecht, H., Resources for the Future (RFF), USA

Haites, E., Margaree Consultants, Canada

Haas, R., Technical University of Vienna, Austria

Harrison, G., University of South Carolina, USA (Australian)

Helm, C., Humboldt University, Germany

Höhne, N., ECOFYS Energy and Environment, Germany 
Hourcade, J.-C., Centre Int. de Recherche sur l'Env. et le Développement (CIRED), France

Huber, C., Vienna University of Technology, Austria

Igarashi, Y., Ministry of Foreign Affairs, Japan

Jacoby, H., MIT, USA

Jensen, J., Copenhagen Economics, Denmark

Jepma, C., University of Groningen, The Netherlands

Jochem, E., Fraunhofer Institute for Systems and Innovation Research (ISI), Germany

Kemfert, C., University of Oldenburg, Germany

Klaasen, G., International Institute for Applied Systems Analysis (IIASA), Austria (Dutch)

Klepper, G., Institute for World Economics, Germany

Kranjc, A., Ministry of Environment, Slovenia

Kratena, K., Austrian Institute of Economic Research (WIFO), Austria

Kristof, K., Wuppertal Institute for Climate, Environment and Energy, Germany

Kverndokk, S., Frisch Centre, Norway

Kypreos, S., Paul Scherrer Institute (PSI), Switzerland (Greek)

Loulou, R., McGill University, Canada

Manders, T., Bureau for Economic Policy Analysis (CPB), The Netherlands

Martinez, E., Ministry of Environment, France

Michaelowa, A., Hamburg Institute of International Economics (HWWA), Germany

Philibert, C., International Energy Agency (IEA), France

Pizer, W., Resources for the Future, USA

Radunsky, K., Federal Environment Agency, Austria

Rana, A., National Institute for Environmental Studies (NIES), Japan (Indian)

Reilly, J., MIT, US

Riahi, K., International Institute for Applied Systems Analysis (IIASA), Austria (Irani)

Rutherford, T.F., University of Colorado, USA

Schrattenholzer, L., International Institute for Applied Systems Analysis (IIASA), Austria

Seebregts, A., Energy Research Centre of the Netherlands (ECN), The Netherlands

Smekens, K., Energy Research Centre of the Netherlands (ECN), The Netherlands

Stephan, G., University of Bern, Switzerland (German)

Stratton, T., Department of Foreign Affairs and International Trada, Canada

Swart, R., Institute for Environmental Studies (IVM), The Netherlands 
Taylor, T., Metroeconomica, UK

Tol, R., University of Hamburg, Germany (Dutch)

Tomoda, T., Research Institute of Innovative Technology for the Earth (RITE), Japan

Torvanger, A., Center for Int. Climate and Environmental Research (CICERO), Norway Abad, F., Colegio de Mexico, Mexico

Tulkens, P., Federal Planning Bureau, Belgium

van der Zwaan, B., Energy Research Centre of the Netherlands (ECN), The Netherlands

van Regemorter, D., K.U. Leuven, Belgium

van Steenberghe, V., Université Catholique de Louvain, Belgium

Vainio, M., European Commission (Finnish)

Velychko, O., Ministry of the Environment and Natural Resources, Ukraine

Verbruggen, A., University of Antwerp, Belgium

Welsch, H., University of Oldenburg, Germany

Woerdman, E., University of Groningen, The Netherlands

Yohe, G., Wesleyan University, USA

Zapfel, P., European Commission (Austrian)

Zhang, Z.X., East-West Center, USA 
Post-Kyoto Climate Policy

A Computable General Equilibrium Analysis

based on Expert Judgements

Christoph Böhringer and Andreas Löschel

Centre for European Economic Research (ZEW)

P.O. Box 1034 43, D-68034 Mannheim, Germany

\section{Downloadable Appendix}

(ftp://ftp.zew.de/pub/zew-docs/div/PostKyoto.pdf)

Appendix A: Expert Poll 
Appendix A: Expert Poll 


\section{Post-Kyoto Commitments: An Expert Poll based on a Cross-Impact Matrix (CIM)}

\section{Objective}

During COP6.5 and COP7 in Bonn and Marrakech, the implementation rules of the Kyoto Protocol for the $1^{\text {st }}$ commitment period were finalized. The Protocol is now ready for ratification. However, there are large uncertainties with respect to the follow-up of climate protection policies in a $2^{\text {nd }}$ commitment period. Our poll is designed to identify key policy scenarios for a $2^{\text {nd }}$ commitment period based on expert opinions. As contributing expert you will receive the summary of results before public release and you will be explicitly mentioned. Your answers will be treated anonymously.

We perform the poll by means of a so-called cross-impact matrix (CIM), which allows for a systematic evaluation of expert opinions. Our cross-impact matrix captures cross-relationships between four key dimensions of a Post-Kyoto commitment: the required emission reduction for the abatement coalition within a $2^{\text {nd }}$ commitment period, U.S. participation, inclusion of developing countries, and the allocation rule for emission entitlements.

You are asked to assess the interrelationship of these dimensions and the initial occurrence probabilities of events characterizing these dimensions within the CIM (attached to the end of this document).

Before you begin, we will briefly lay out the overall policy benchmark (see section 1), the scenario dimensions and specific events (see section 2), and the rules about how to fill out the cross-impact matrix (see section 3). For optional use, we have prepared an additional spreadsheet in the Appendix will provide you with the effective emission reduction requirements for central regions that are forming an abatement coalition under alternative allocation rules and global reduction targets.

Please read carefully before you start the CIM. If you have comments or questions on the design of our poll, please address loeschel@zew.de 


\section{Policy Benchmark}

The Kyoto Protocol is likely to be ratified during 2002. We assume that the Kyoto Protocol will enter into force for its $1^{\text {st }}$ commitment period between $2008-2012$. The U.S. will keep with its withdrawal for the $1^{\text {st }}$ commitment period. Furthermore, we assume that U.S. withdrawal, carbon sink credits, unrestricted permit trading, and larger hot air supplies from Russia and Ukraine will substantially relax the stringency of the Kyoto targets for signatory industrialized countries. Environmental effectiveness and compliance costs will be rather small even if Russia and Ukraine do act as monopoly suppliers of permits (restricting their supply of hot air). The recent Climate Change Plan for the US announced by President Bush on February 14, 2002 codifies more or less business-as-usual (BaU) emissions for the US.

In this context, the US and other industrialized countries (as listed in Annex B of the Kyoto Protocol) as well as the developing countries will negotiate on the design of a $2^{\text {nd }}$ Post-Kyoto commitment period till 2020 . For the sake of simplicity and data availability, we refer to the $2^{\text {nd }}$ commitment period as lasting from 2010-2020, where the starting point 2010 represents simply $\mathrm{BaU}$ due to the reasons mentioned above. Without a $2^{\text {nd }}$ commitment, i.e. under business-as-usual, global emissions will rise between 2010 and 2020 by $25 \%$. We assume that members of the abatement coalition for the $2^{\text {nd }}$ commitment period can freely trade in emission rights among each other.

In our abatement scenarios, we have deliberately omitted tax- or price-based regimes to cope with uncertainties, since we adopt a deterministic view on the future development of economic development and associated emissions.

\section{Overview of Dimensions and Events}

The CIM incorporates four key dimensions - A through D - of a Post-Kyoto commitment that are characterized by alternative events (see also Table 1 for a complete listing):

A Required global emission reduction (relative to $2020 \mathrm{BaU}$ level) suggests four global emission reduction targets with respect to the business-as-usual emission level in 2020. Reduction zero (event $\mathrm{a}_{1}$ ) reflects a situation without any emission abatement, i.e. 0\% reduction. The remaining three reduction requirements are in line with alternative longterm IPCC stabilization targets of atmospheric $\mathrm{CO}_{2}$ concentrations in 2100: low (event $\mathrm{a}_{2}$ ) 
represents a $10 \%$ emission reduction (650 ppmv in 2100), middle (event $\mathrm{a}_{3}$ ) represents a $20 \%$ emission reduction (550 ppmv in 2100), and high (event $\mathrm{a}_{4}$ ) represents a $30 \%$ emission reduction (450 ppmv in 2100). The global emission reduction must be achieved by 2020 by the abatement coalition. For example: If the abatement coalition consists only of industrialized countries, the latter must carry the whole global abatement burden while developing countries can proceed as under business-as-usual.

B US participation in the abatement coalition will be the case (event $b_{1}:$ yes) or not. If the US is not member of the abatement coalition, it is either allowed to sell project-based emission reductions (event $\mathrm{b}_{2}$ : no/trade) or not (event $\mathrm{b}_{3}: n o$ ).

C Participation of developing countries in the abatement coalition will be the case (event $\mathrm{c}_{1}:$ yes) or not. If developing countries are not members of the abatement coalition, they are either allowed to sell project-based emission reductions (event $\mathrm{c}_{2}:$ no/trade) or not (event $\mathrm{c}_{3}:$ no).

D Equity principle considers four alternative burden-sharing rules of how the overall emission budget is translated into emission entitlements or emission reduction obligations:

- egalitarian (event $\mathrm{d}_{1}$ ): Emission entitlements will be shared in equal-per-capita proportions based on population figures for 2010 .

- ability-to-pay (event $\mathrm{d}_{2}$ ): The absolute reduction requirement between 2010 and 2020 will be shared by regions according to their shares in GDP for the year 2010. The higher a region's share in GDP is, the higher its reduction requirement will be. Example: If a region has $70 \%$ of the abatement coalition's total GDP in 2010, it is assigned $70 \%$ of the absolute reduction requirement that the coalition has to undertake.

- polluter pays (event $\mathrm{d}_{3}$ ): The absolute reduction requirement between 2010 and 2020 will be shared by regions according to their shares in emissions for the year 2010. The higher a region's share in 2010 emissions is, the higher its reduction obligation will be. - sovereignty (event $\mathrm{d}_{4}$ ): Emission entitlements will be shared in proportion to the emissions in 2010. 
Table 1: Dimensions and events of Post-Kyoto-Scenarios for 2010-2020

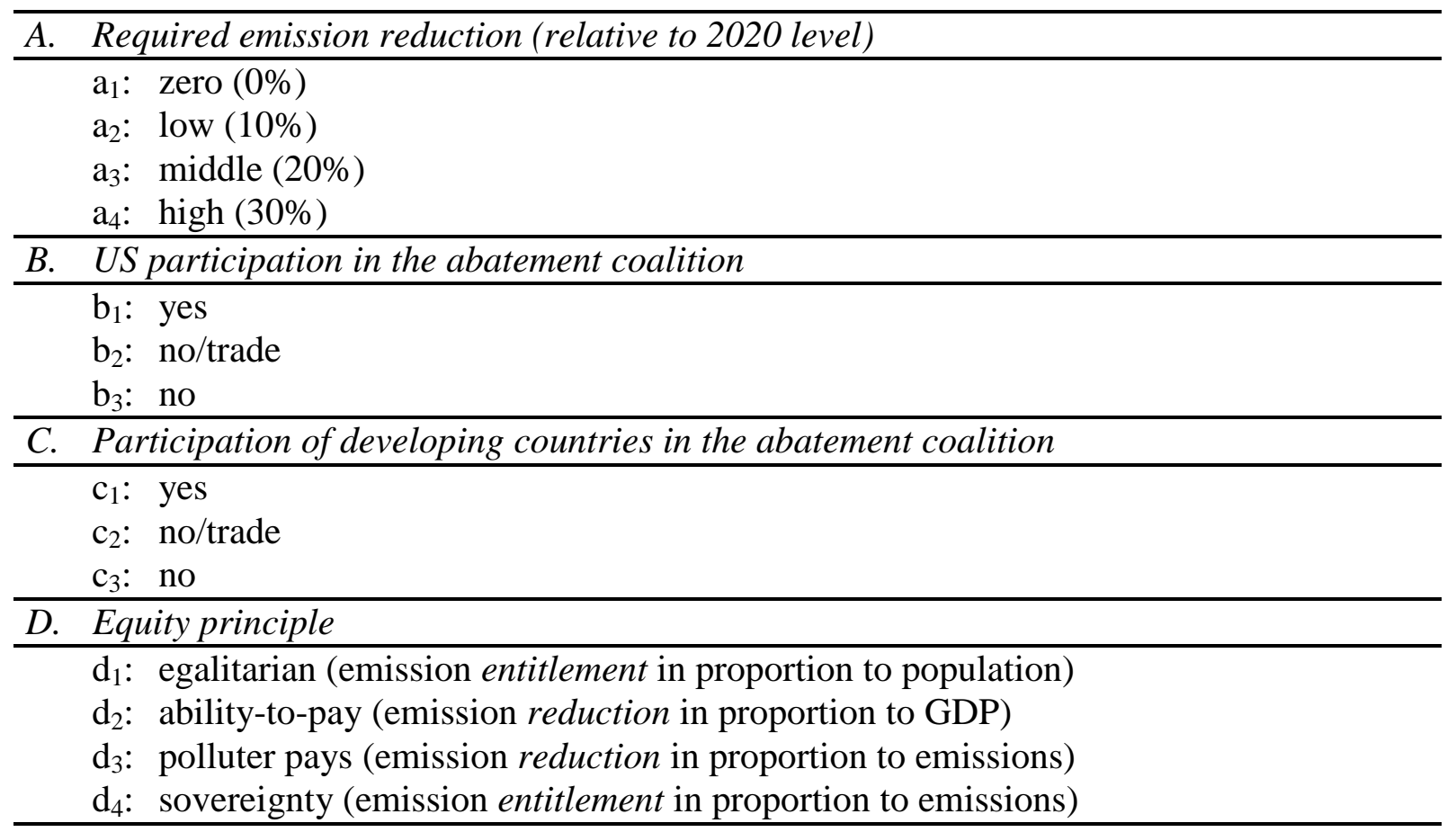

\section{Rules for Filling out the CIM}

The events in the rows are the impact source for the events in the columns of the matrix (impact sinks). At each matrix intersection, the following question is asked: If the event in the row were to occur, how would it affect the probability of occurrence of the event in the column. Only quantify the direct impact! All indirect impacts will be accounted for automatically by means of the CIM method. Judgements are entered in the matrix cells. The probability of occurrence can be indicated with 7 different scales ranging from (-3) "reduces probability of occurrence significantly" to $(+3)$ "increases probability of occurrence significantly". For example: If you think that the adoption of the egalitarian equity principle (occurrence of event $\mathrm{d}_{1}$ ) "reduces significantly" the probability of US participation (occurrence of event $b_{1}$ ), then insert “- 3 " in the matrix cell given by the intersection of row $d_{1}$ and column $b_{1}$.

In the last column of the CIM you must enter the initial occurrence probability of each event. Initial occurrence probabilities across all events within one scenario dimension must sum up to one!

Judgement may only be entered in the boxes of the CIM. Please fill in also your personnel information. The poll will be evaluated anonymously. 


\section{Appendix: Reduction Scenarios and Effective Reduction Requirements}

Based on the most recent International Energy Outlook (IEO 2001: reference case) issued by the US Department of Energy, we have performed calculations to give an idea of which effective emission reduction requirements emerge across regions for the different scenarios. Table 2 lists the reduction requirements under the different scenarios for two geopolitical regions: North (industrialized world without US) and South (developing countries). The US is listed separately. Negative entries indicate a permissible increase in emissions over BaU emission levels in 2020.

Table 2: Effective Reduction Requirement in \% vs. 2020 BaU emissions

\begin{tabular}{|c|c|c|c|c|}
\hline & egalitarian $\left(\mathrm{d}_{1}\right)$ & ability-to-pay $\left(\mathrm{d}_{2}\right)$ & polluter pays $\left(\mathrm{d}_{3}\right)$ & sovereignty $\left(\mathrm{d}_{4}\right)$ \\
\hline & \multicolumn{4}{|c|}{ Required emission reduction relative to 2020 level: zero $\left(a_{1}\right)-0 \%$} \\
\hline \multicolumn{5}{|c|}{ US included $\left(b_{1}\right)$ and DC included $\left(c_{1}\right)$} \\
\hline North & 49 & 0 & 0 & -11 \\
\hline South & -68 & 0 & 0 & 12 \\
\hline US & 79 & 0 & 0 & -10 \\
\hline \multicolumn{5}{|c|}{ US included $\left(b_{1}\right)$ and DC excluded $\left(c_{2}\right.$ or $\left.c_{3}\right)$} \\
\hline North & -31 & 0 & 0 & 0 \\
\hline US & 46 & 0 & 0 & 0 \\
\hline \multicolumn{5}{|c|}{ US excluded $\left(b_{2}\right.$ or $\left.b_{3}\right)$ and DC included $\left(c_{1}\right)$} \\
\hline North & 58 & 0 & 0 & -14 \\
\hline South & -39 & 0 & 0 & 9 \\
\hline \multicolumn{5}{|c|}{ US excluded $\left(b_{2}\right.$ or b $\left._{3}\right)$ and DC excluded $\left(c_{2}\right.$ or $\left.c_{3}\right)$} \\
\hline \multirow[t]{2}{*}{ North } & 0 & 0 & 0 & 0 \\
\hline & Required em & ission reduction $\mathbf{r}$ & elative to 2020 leve & l: low $\left(a_{2}\right)-10 \%$ \\
\hline \multicolumn{5}{|c|}{ US included $\left(b_{1}\right)$ and $D C$ included $\left(c_{1}\right)$} \\
\hline North & 54 & 15 & 11 & 0 \\
\hline South & -51 & 5 & 9 & 21 \\
\hline US & 81 & 14 & 11 & 1 \\
\hline \multicolumn{5}{|c|}{ US included $\left(b_{1}\right)$ and $D C$ excluded $\left(c_{2}\right.$ or $\left.c_{3}\right)$} \\
\hline North & -6 & 19 & 19 & 19 \\
\hline US & 57 & 19 & 19 & 19 \\
\hline \multicolumn{5}{|c|}{ US excluded $\left(b_{2}\right.$ or $\left.b_{3}\right)$ and DC included $\left(c_{1}\right)$} \\
\hline North & 63 & 21 & 14 & 1 \\
\hline South & -21 & 7 & 11 & 21 \\
\hline \multicolumn{5}{|c|}{ US excluded $\left(b_{2} \mathrm{or}_{3}\right)$ and DC excluded $\left(c_{2}\right.$ or $\left.c_{3}\right)$} \\
\hline North & 32 & 32 & 32 & 32 \\
\hline
\end{tabular}


Table 2: continued

\begin{tabular}{|c|c|c|c|c|}
\hline & egalitarian $\left(\mathrm{d}_{1}\right)$ & ability-to-pay $\left(\mathrm{d}_{2}\right.$ & polluter pays $\left(\mathrm{d}_{3}\right)$ & sovereignty $\left(\mathrm{d}_{4}\right)$ \\
\hline & \multicolumn{4}{|c|}{ Required emission reduction relative to 2020 level: middle $\left(a_{3}\right)-20 \%$} \\
\hline \multicolumn{5}{|c|}{ US included $\left(b_{1}\right)$ and DC included $\left(c_{1}\right)$} \\
\hline North & 59 & 29 & 22 & 11 \\
\hline South & -34 & 10 & 18 & 29 \\
\hline US & 83 & 29 & 22 & 12 \\
\hline \multicolumn{5}{|c|}{ US included $\left(b_{1}\right)$ and DC excluded $\left(c_{2}\right.$ or $\left.c_{3}\right)$} \\
\hline North & 19 & 38 & 38 & 38 \\
\hline US & 67 & 38 & 38 & 38 \\
\hline \multicolumn{5}{|c|}{$U S$ excluded $\left(b_{2}\right.$ or $\left.b_{3}\right)$ and $D C$ included $\left(c_{1}\right)$} \\
\hline North & 68 & 42 & 29 & 15 \\
\hline South & -4 & 14 & 23 & 32 \\
\hline \multicolumn{5}{|c|}{$U S$ excluded $\left(b_{2}\right.$ or $\left._{3}\right)$ and $D C$ excluded $\left(c_{2}\right.$ or $\left.c_{3}\right)$} \\
\hline North & 63 & 63 & 63 & 63 \\
\hline \multicolumn{5}{|c|}{ Required emission reduction relative to 2020 level: high $\left(a_{4}\right)-30 \%$} \\
\hline \multicolumn{5}{|c|}{ US included $\left(b_{1}\right)$ and $D C$ included $\left(c_{1}\right)$} \\
\hline North & 64 & 44 & 33 & 23 \\
\hline South & -17 & 15 & 26 & 38 \\
\hline US & 85 & 43 & 33 & 23 \\
\hline \multicolumn{5}{|c|}{ US included $\left(b_{1}\right)$ and DC excluded $\left(c_{2}\right.$ or $\left.c_{3}\right)$} \\
\hline North & 44 & 57 & 57 & 57 \\
\hline US & 77 & 56 & 57 & 57 \\
\hline \multicolumn{5}{|c|}{ US excluded $\left(b_{2}\right.$ or $\left.b_{3}\right)$ and DC included $\left(c_{1}\right)$} \\
\hline North & 74 & 63 & 43 & 29 \\
\hline South & 14 & 21 & 34 & 44 \\
\hline \multicolumn{5}{|c|}{ US excluded $\left(b_{2}\right.$ or $\left._{3}\right)$ and $D C$ excluded $\left(c_{2}\right.$ or $\left.c_{3}\right)$} \\
\hline North & 95 & 95 & 95 & 95 \\
\hline
\end{tabular}




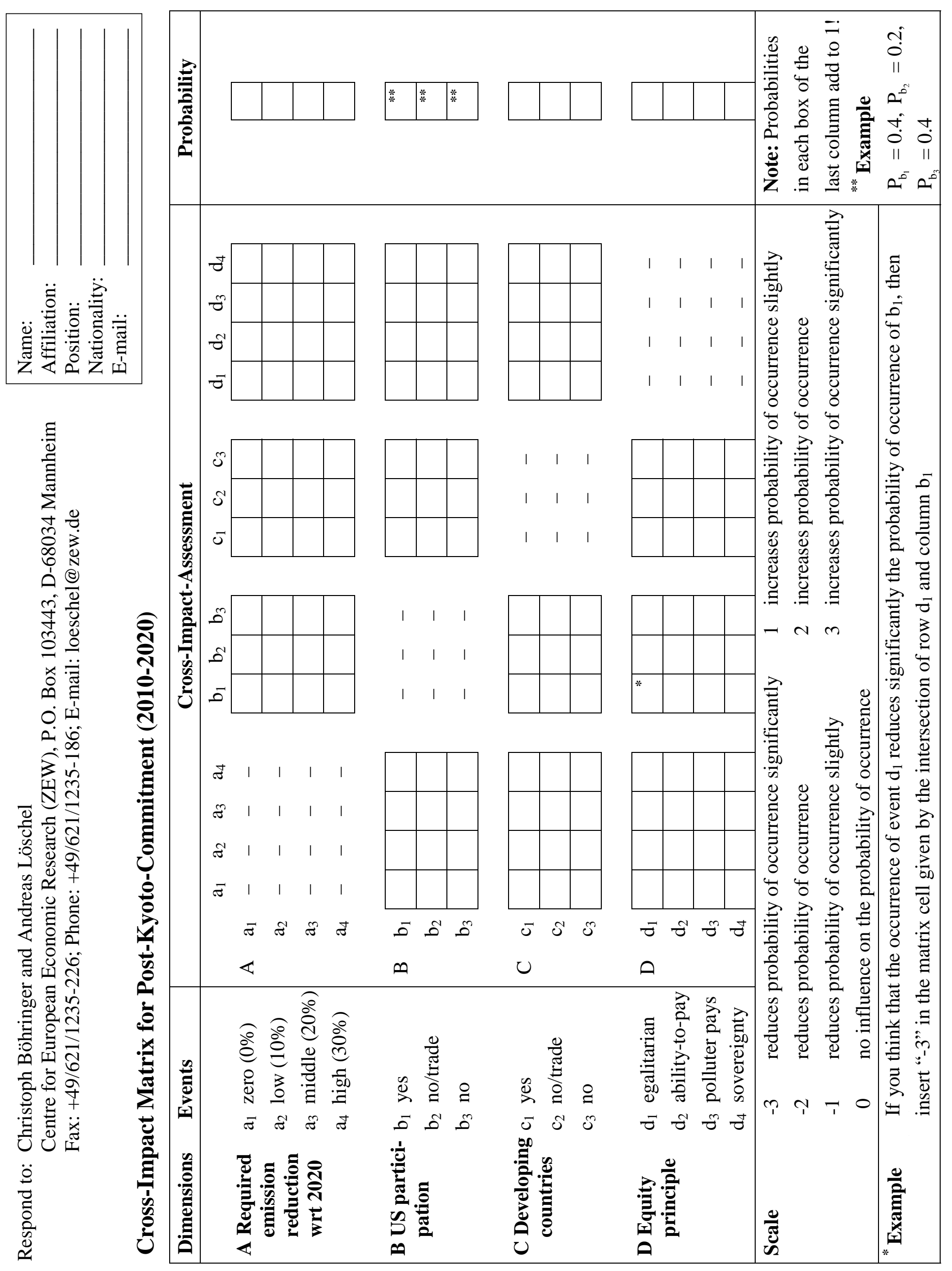


Appendix B: Cross-Impact Model 
Cross-impact analysis was initially suggested by T. Gordon and O. Helmer in KaiserAluminium's FUTURE game (Gordon and Hayward, 1968; Helmer, 1972). The first step to implement a cross-impact model is the definition of the set of possible future events $A_{i}$ with $m$ descriptors $\left(D_{1}, \ldots, D_{m}\right)$, each of which can take on $n_{j} \in \mathbb{N}$ different states $(j=1, \ldots, m)$. Overall, there are $n=\sum_{j=1}^{m} n_{j}$ different descriptor states (events) $A_{1}, \ldots, A_{n}$ (or, if a double index is used in which the first index describes the descriptor and the second index the state, $\left.A_{11}, \ldots, A_{m n_{m}}\right)$. As to further notation: $\tilde{n}_{i}=\sum_{j=1}^{i} n_{j}$. If a descriptor $D_{i}$ takes on the state $A_{i j}$, then $A_{i j}=1$ and allother $A_{i v}=0$ for $v \neq j$. Altogether, there is a set of $S$ different scenarios with $|S|=\prod_{j=1}^{m} n_{j}$, which yields $x_{s}$ scenario probabilities to be estimated $(s \in\{1, \ldots,|S|\})$. The scenario probabilities assess the joint occurrence of the $m$ states of the respective scenarios.

The basic concept of cross-impact analysis is that the occurrence of an event $A_{i}$ will affect the likelihood that other events $A_{j}$ will occur. The strength and mode (unrelated, inhibiting or enhancing) of the interaction between event $A_{i}$ and event $A_{j}$ are characterized by cross-impact numbers $k_{i j}$ (in our case: $k_{i j} \in\{-3, \ldots, 3\}$ ), which form a cross-impact matrix $K_{n \times n}=\left(k_{i j}\right)$. Among the individual matrix elements, $n^{2}-\sum_{i=1}^{m} n_{i}^{2}$ potential interactions ("cross impacts") have to be assessed. The diagonal block sub-matrices are set to zero.

Let $p_{j}$ denote the subjective estimate of the a priori (marginal) probability of occurrence of event $A_{j}$, where $p_{j} \in[0,1] \forall j$ and $\sum_{j=\tilde{n}_{i-1}+1}^{\tilde{n}_{i}} p_{j}=1 \forall i$. The future states of descriptors are defined such that at least one of them will occur in the future - however, one does not know in advance which. For the sake of convenience, we use a single index notation hereafter and assume that the indices refer to states of different descriptor. The joint probability of the set of events $\left(A_{i_{1}}, \ldots, A_{i_{l}}\right), l \in\{2, \ldots, m\}$ and $i_{j} \in\{1, \ldots, n\}$, is given by $p_{i_{1}, \ldots, i_{l}}$. Since the estimation of higher-order probabilities turns out to be extremely difficult (Mitchell et al. 1977), we simulate the joint probabilities for interdependent events, most importantly the scenario probabilities. We modify the BASICS simulation technique as proposed by Honton et al. (1984) for scenario generation using only estimations of marginal probabilities together with cross impacts in order to determine the joint scenario probabilities $x_{s}$.

Within our poll, the expert assesses the future of climate protection in terms of potential interactions and probabilities of events. We have considered $m=4$ events with $n_{l}=$ 
4, $n_{2}=3, n_{3}=3$, and $n_{4}=4$ different states. Thus, there are $n=14$ different descriptors and marginal probabilities to be estimated. $|S|$ amounts to $4 \cdot 3 \cdot 3 \cdot 4=144$ different scenarios while the experts must assess $14^{2}-\left(4^{2}+3^{2}+3^{2}+4^{2}\right)=146$ cross impacts. Once the elements of the cross-impact model have all been specified, we use a Monte Carlo technique to obtain a representative random sample. (Note that the BASICS method differs from our approach in that no Monte Carlo simulations performed.)

In order to generate a single scenario from the total set of marginal probability $p_{i}$ and cross-impact information $k_{i j}$, we apply the following four-step heuristic procedure (see also Mißler-Behr, 1993):

1. Select an event $A_{j}$ at random and decide its occurrence or non-occurrence on the basis of the assigned a priori probabilities.

The first event $A_{j}$ is selected at random taking into account the expert assessment of marginal probabilities. A random number generator is used to decide whether $A_{j}$ occurs or not. Next, the marginal probability of the selected event $A_{j}$ gets adjusted: $p_{j}=1$ in the case of occurrence and $p_{j}=0$ in the case of non-occurrence. In the case of event occurrence, all other marginal probabilities $p_{\mu}$ of the different states of the respective descriptor $D_{l}, \mu \in\left\{\tilde{n}_{l-1}+1, \ldots, \tilde{n}_{l}\right\}$ and $\mu \neq j$, are set to zero.

2. Adjust the probability of the remaining events $A_{i}$ according to the cross impacts assessed by the experts.

The cross impacts $k_{i j}$ describe the impacts of occurrence of event $A_{j}$ on $A_{i}$. In addition, we have to estimate $\bar{k}_{i j}$, i.e. the interactions between $A_{j}$ on $A_{i}$ in the case of non-occurrence of event $A_{j}$. Since in the case of non-occurrence of state $A_{j}$ of descriptor $D_{l}$ another state $A_{\mu}(\mu \in$ $\left\{\tilde{n}_{l-1}+1, \ldots, \tilde{n}_{l}\right\}$ and $\mu \neq j$ ) of descriptor $D_{l}$ must occur affecting $A_{i}$, the impact of nonoccurrence of $A_{j}$ is estimated as the average impact of the occurrence of all other states $A_{\mu}$ of descriptor $D_{l}$ on $A_{i}: \bar{K}_{n \times n}=\left(\bar{k}_{j i}\right)=$ round $\left[\sum_{\substack{\mu \neq \tilde{n}_{l-1+1}+1 \\ \mu \neq j}}^{\tilde{n}_{\mu i}} /\left(n_{l}-1\right)\right]$. In case of occurence of event $A_{j}$, the cross impacts $k_{j i}$ are transformed into a cross-impact factor $f_{j i}$ to generate a crossimpact factor matrix: 
$F_{n \times n}=\left(f_{j i}\right)$ with $f_{j i}= \begin{cases}k_{j i}+1 & \text { for } k_{j i} \geq 0 \\ \frac{1}{\left|k_{j i}\right|+1} & \text { for } k_{j i}<0\end{cases}$

In the case of non-occurrence of $A_{j}$ the matrix $F$ is built using $\bar{k}_{j i}$ instead of $k_{j i}$. From the odds of occurrence of event $A_{i}, w_{i} \in[0, \infty], w_{i}=p_{i} /\left(1-p_{i}\right)$, the probability of occurrence can be derived as $p_{i}=w_{i} /\left(1-w_{i}\right)$. The occurrence of event $A_{j}$ changes the odds of $A_{i}$ depending on the cross-impact factor $f_{j i}: w_{i(j)}=w_{i} \cdot f_{j i}$. The odds are reduced if $A_{j}$ has an inhibiting impact on $A_{i}$, i.e. $f_{j i} \in(0,1)$. They remain unchanged if $A_{j}$ has no impact on $A_{i}$, i.e. $f_{j i}=1$, and the odds are increased if $A_{j}$ has an enhancing impact on $A_{i}$, i.e. $f_{j i}>1$. The adjusted probability $p_{i(j)}$ of $A_{i}$ is given by $p_{i(j)}=w_{i(j)} /\left(1-w_{i(j)}\right)=p_{i} \cdot f_{j i} /\left[1-p_{i}\left(f_{j i}-1\right)\right]$. As the adjusted probabilities of each descriptor do not necessarily add up to one, the $p_{i(j)}$ 's for all events are normalized. The normalized adjusted probability of state $A_{i}$ of descriptor $D_{l}$ is given by: $p_{i(j)}^{\prime}=p_{i(j)} / \sum_{\mu=\tilde{n}_{l-1}+1}^{\tilde{n}_{l}} p_{\mu(j)}, i \in\left\{\tilde{n}_{l-1}+1, \ldots, \tilde{n}_{l}\right\}$.

3. Select another event $A_{l}$ among the remaining ones and decide its occurrence or nonoccurrence on the basis of the adjusted probabilities.

To select another event the distance $d_{i}, i=1, \ldots, n ; d_{i} \in[0,0,5]$ of all adjusted event probabilities $p_{i(j)}^{\prime}$ to zero or one is calculated:

$d_{i}=\left\{\begin{array}{lll}p_{i(j)}^{\prime} & \text { for } & p_{i(j)}^{\prime}<0.5 \\ 1-p_{i(j)}^{\prime} & \text { for } & p_{i(j)}^{\prime} \geq 0.5\end{array}\right.$

The closer $p_{i(j)}^{\prime}$ comes to zero, the more probable it is that $A_{i}$ does not occur. The closer $p_{i(j)}^{\prime}$ comes to one, the more probable it is that $A_{i}$ occurs. Therefore, the next event $A_{l}$ is chosen according to the following rule: $\left(\min _{i \in\{1, \ldots n\}} d_{i}=d_{l}\right) \wedge\left(d_{l}>0\right)$. Whenever $0<p_{l(j)}^{\prime}<0.5$, it is assumed that $A_{l}$ occurs. If $0.5 \leq p_{l(j)}^{\prime}<1$, it is assumed that $A_{l}$ does not occur. In case $\left(\min _{i} d_{i}\right)$ is not unambiguous, a random number generator is used to select an event. The 
condition $\left(d_{l}>0\right)$ assures that only events are selected for which adjusted probabilities are not already set to zero or one.

4. Continue Step 2 and Step 3 until all events in the set have been decided.

One simulation run is finished as soon as all events have either occurred or not occurred. The result of the simulation is one scenario.

In our application, the simulation procedure is repeated 100 times for each of the 79 experts' cross-impact matrices. This yields a set of marginal probabilities and scenario probabilities that adequately represents the interaction between a number of uncertain developments. Figure B.1 summarizes the simulation procedure in use to derive the scenario probabilities.

Figure B.1: Simulation procedure

for 79 Cross-Impact-Matrices
\begin{tabular}{l|l|}
\hline \multicolumn{1}{|l|}{ for 100 starting points } \\
$\qquad \begin{array}{l}\text { adjust probabilities } \\
\text { normalize probabilities } \\
\text { choose next state }\end{array}$ \\
\hline
\end{tabular}




\section{Appendix C: CGE Model Summary}




\section{Non-technical model description}

Figure C.1 provides a diagrammatic structure of the multi-region, multi-sector CGE model underlying our comparative-static analysis of Post-Kyoto policy scenarios. Primary factors of

region $r$ include labor $\bar{L}_{r}$, capital $\bar{K}_{r}$, and fossil-fuel resources $\bar{Q}_{f f, r}$. Labor and capital are intersectorally mobile within a region but cannot move between regions. A specific resource is used in the production of fossil fuels $f f$ (crude oil, coal and gas), resulting in upward sloping supply schedules.

Production $Y_{i r}$ of commodities $i$ in region $r$ other than primary fossil fuels is captured by aggregate production functions which characterize technology through substitution possibilities between various inputs. Nested constant elasticity of substitution (CES) cost functions with three levels are employed to specify the substitution possibilities in domestic production between capital, labor, energy and non-energy, intermediate inputs, i.e. material. At the top level, non-energy inputs are employed in fixed proportions with an aggregate of energy, capital and labor. At the second level, a CES function describes the substitution possibilities between the energy aggregate and the aggregate of labor and capital. Finally, at the third level, capital and labor trade off with a constant elasticity of substitution. As to the formation of the energy aggregate, we allow sufficient levels of nesting to permit substitution between primary energy types, as well as substitution between a primary energy composite and secondary energy, i.e. electricity.

Final demand $C_{r}$ in each region is determined by a representative agent $R A_{r}$, who maximizes utility subject to a budget constraint with fixed investment. Total income of the representative household consists of factor income and tax revenues. Final demand of the representative agent is given as a CES composite which combines consumption of an energy aggregate with a non-energy consumption bundle. Substitution patterns within the non-energy consumption bundle are reflected via Cobb-Douglas functions. The energy aggregate in final demand consists of the various energy goods trading off at a constant elasticity of substitution.

All goods used on the domestic market in intermediate and final demand correspond to a CES composite $A_{i r}$ of the domestically produced variety and a CES import aggregate $M_{i r}$ of the same variety from the other regions (the so-called Armington good - see Armington, 1969). Domestic production either enters the formation of the Armington good or is exported to satisfy the import demand of other regions. 
The tax system includes all types of indirect taxes (production taxes or subsidies ty, intermediate taxes $t i$, consumption taxes $t c$, as well as tariffs $t m$ and $t x$ ) which are used to finance a fixed level of public good provision. A lump-sum tax on the representative household balances the public budget.

Benchmark data determine parameters of the functional forms from a given set of benchmark quantities, prices, and elasticities. The underlying data base is GTAP-EG for the year 1997 which provides a consistent representation of energy markets in physical units as well as detailed accounts of regional production and consumption as well as bilateral trade flow (see McDougall et al., 1998; Rutherford and Paltsev, 2000). The benchmark data, and the regional and sectoral aggregation are described in section Benchmark Data-Regional and Sectoral Aggregation of this Appendix.

The economic effects of future climate policies depend on the extent to which emission reduction targets constrain the respective economies in their $\mathrm{BaU}$ development (without emission limits). Thus, the magnitude and distribution of adjustment costs to Post-Kyoto commitments depend on the $B a U$ projections for GDP, fuel prices, energy efficiency improvements, etc. In our comparative-static framework, we infer the $B a U$ structure of the model's regions for the target year (in our case: 2020) using recent projections for economic development from the International Energy Outlook (DOE, 2001) (see section Baseline Projections - Forward Calibration of this Appendix). We then measure the costs of abatement relative to that baseline.

Numerically, the model is formulated as a mixed complementarity problem (MCP) in GAMS (Brooke et al. 1996; Rutherford, 1999) and solved using PATH (Dirkse and Ferris, 1995).

\section{Algebraic model description}

Two classes of conditions characterize the competitive equilibrium for our model: zero profit conditions and market clearance conditions. The former class determines activity levels and the latter determines price levels. In our algebraic exposition, the notation $\Pi_{i r}^{z}$ is used to denote the profit function of sector $j$ in region $r$ where $z$ is the name assigned to the associated production activity. Differentiating the profit function with respect to input and output prices provides compensated demand and supply coefficients (Hotelling's lemma), which appear subsequently in the market clearance conditions. 



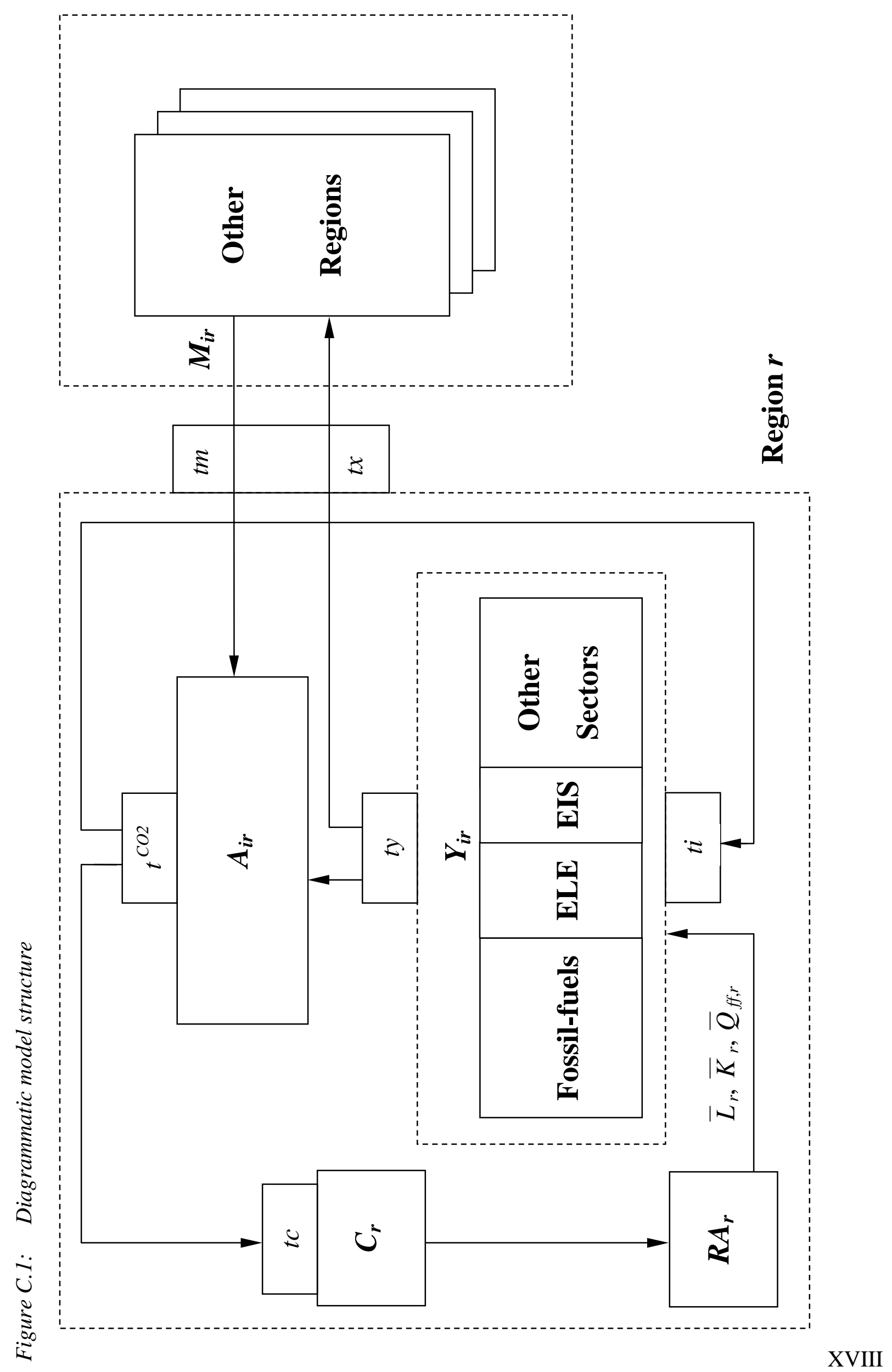


We use $i$ (aliased with $j$ ) as an index for commodities (sectors) and $r$ (aliased with $s$ ) as an index for regions. The label $E G$ represents the set of energy goods and the label $F F$ denotes the subset of fossil fuels. Tables C.1 - C.6 explain the notations for variables and parameters employed within our algebraic exposition. Figures C. 1 - C. 4 provide a graphical exposition of the production and final consumption structure.

\section{Zero Profit Conditions}

1. Production of goods except fossil fuels:

$\prod_{i r}^{Y}=\left(\theta_{i r}^{X} p_{i r}^{X^{1-\eta}}+\left(1-\theta_{i r}^{X}\right) p_{i r}^{1-\eta}\right)^{\frac{1}{1-\eta}}-\sum_{j \notin E G} \theta_{j i r} p_{j r}^{A}-\theta_{i r}^{K L E}\left[\theta_{i r}^{E} p_{i r}^{E}{ }^{1-\sigma_{K L E}}+\left(1-\theta_{i r}^{E}\right)\left(w_{r}^{\alpha_{j r}^{L}} v_{r}^{\alpha_{r r}^{K}}\right)^{I-\sigma_{K L E}}\right]^{1-\sigma_{K L E}}=0 \quad \mathrm{i} \notin \mathrm{FF}$

2. Production of fossil fuels:

$$
\prod_{i r}^{Y}=\left(\theta_{i r}^{X} p_{i r}^{X^{1-\eta}}+\left(1-\theta_{i r}^{X}\right) p_{i r}^{1-\eta}\right)^{\frac{1}{1-\eta}}-\left[\theta_{i r}^{Q} q_{i r}^{1-\sigma_{Q, i}}+\left(1-\theta_{i r}^{Q}\right)\left(\theta_{L i r}^{F F} w_{r}+\theta_{K i r}^{F F} v_{r}+\sum_{j} \theta_{j i r}^{F F} p_{j r}^{A}\right)^{1-\sigma_{Q, i}}\right]^{\frac{1}{1-\sigma_{Q, i}}}=0 \quad \mathrm{i} \in \mathrm{FF}
$$

3. Sector-specific energy aggregate:

$$
\prod_{i r}^{E}=p_{i r}^{E}-\left\{\theta_{i r}^{E L E} p_{\{E L E, r\}}^{A^{1-\sigma_{E L E}}}+\left(1-\theta_{i r}^{E L E}\right)\left[\theta_{i r}^{C O A} p_{\{C O A, r\}}^{A^{1-\sigma_{C O A}}}+\left(1-\theta_{i r}^{C O A}\right)\left(\prod_{j \in L Q} p_{j r}^{A^{\beta_{j i r}}}\right)^{1-\sigma_{C O A}}\right]^{\frac{1-\sigma_{E L E}}{1-\sigma_{C O A}}}\right\}^{\frac{1}{1-\sigma_{E L E}}}=0
$$

4. Armington aggregate:

$$
\prod_{i r}^{A}=p_{i r}^{A}-\left[\left(\theta_{i r}^{A} p_{i r}^{l-\sigma_{A}}+\left(1-\theta_{i r}^{A}\right) p_{i r}^{M^{1-\sigma_{A}}}\right)^{\frac{1}{1-\sigma_{A}}}+t_{r}^{C O 2} a_{i}^{C O 2}\right]=0
$$

5. Aggregate imports across import regions:

$$
\prod_{i r}^{M}=p_{i r}^{M}-\left(\sum_{s} \theta_{i s r}^{M} p_{i s}^{X}{ }^{1-\sigma_{M}}\right)^{\frac{1}{1-\sigma_{M}}}=0
$$

6. Household consumption demand:

$$
\left.\prod_{r}^{C}=p_{r}^{C}-\left(\theta_{C r}^{E} p_{C r}^{E l-\sigma_{E C}}+\left(1-\theta_{C r}^{E}\right)\left[\prod_{i \notin F F} p_{i r}^{A^{\gamma_{i r}}}\right)\right]^{I-\sigma_{E C}}\right)^{\frac{1}{1-\sigma_{E C}}}=0
$$

7. Household energy demand:

$$
\prod_{C r}^{E}=p_{C r}^{E}-\left[\sum_{i \in F F} \theta_{i C r}^{E} p_{i r}^{A}{ }^{l-\sigma_{F F, C}}\right]^{\frac{1}{1-\sigma_{F F, C}}}=0
$$




\section{Market Clearance Conditions}

8. Labor:

$$
\bar{L}_{r}=\sum_{i} Y_{i r} \frac{\partial \prod_{i r}^{Y}}{\partial w_{r}}
$$

9. Capital:

$$
\bar{K}_{r}=\sum_{i} Y_{i r} \frac{\partial \prod_{i r}^{Y}}{\partial v_{r}}
$$

10. Natural resources:

$$
\bar{Q}_{i r}=Y_{i r} \frac{\partial \prod_{i r}^{Y}}{\partial q_{i r}} \quad i \in F F
$$

11. Output for domestic markets:

$$
Y_{i r} \frac{\partial \prod_{i r}^{Y}}{\partial p_{i r}}=\sum_{j} A_{j r} \frac{\partial \prod_{j r}^{A}}{\partial p_{i r}}
$$

12. Output for export markets:

$$
Y_{i r} \frac{\partial \prod_{i r}^{Y}}{\partial p_{i r}^{X}}=\sum_{s} M_{i s} \frac{\partial \prod_{i s}^{M}}{\partial p_{i r}^{X}}
$$

13. Sector specific energy aggregate:

$$
E_{i r}=Y_{i r} \frac{\partial \prod_{i r}^{Y}}{\partial p_{i r}^{E}}
$$

14. Import aggregate:

$$
M_{i r}=A_{i r} \frac{\partial \Pi_{i r}^{A}}{\partial p_{i r}^{M}}
$$

15. Armington aggregate:

$$
A_{i r}=\sum_{j} Y_{j r} \frac{\partial \prod_{j r}^{Y}}{\partial p_{i r}^{A}}+C_{r} \frac{\partial \prod_{r}^{C}}{\partial p_{i r}^{A}}
$$

16. Household consumption:

$$
C_{r} p_{r}^{C}=w_{r} \bar{L}_{r}+v_{r} \bar{K}_{r}+\sum_{j \in F F} q_{j r} \bar{Q}_{j r}+t_{r}^{C O 2} \overline{C O 2}_{r}+p_{C G D, r} \bar{Y}_{C G D, r}+\bar{B}_{r}
$$

17. Aggregate household energy consumption:

$$
E_{C r}=C_{r} \frac{\partial \prod_{r}^{C}}{\partial p_{C r}^{E}}
$$

18. Carbon emissions:

$$
\overline{\mathrm{CO}}_{r}=\sum_{i} A_{i r} a_{i}^{\mathrm{CO} 2}
$$


Table C.1: Sets

\begin{tabular}{ll}
\hline I & Sectors and goods \\
$\mathrm{J}$ & Aliased with i \\
$\mathrm{R}$ & Regions \\
$\mathrm{S}$ & Aliased with $\mathrm{r}$ \\
$\mathrm{EG}$ & All energy goods: Coal, crude oil, refined oil, gas and electricity \\
$\mathrm{FF}$ & Primary fossil fuels: Coal, crude oil and gas \\
LQ & Liquid fuels: Crude oil and gas \\
\hline
\end{tabular}

Table C.2: Activity variables

\begin{tabular}{ll}
\hline$Y_{i r}$ & Production in sector $i$ and region $r$ \\
$E_{i r}$ & Aggregate energy input in sector $i$ and region $r$ \\
$M_{i r}$ & Aggregate imports of good $i$ and region $r$ \\
$A_{d i r}$ & Armington aggregate for demand category $d$ of good $i$ in region $r$ \\
$C_{r}$ & Aggregate household consumption in region $r$ \\
$E_{C r}$ & Aggregate household energy consumption in region $r$ \\
\hline
\end{tabular}

Table C.3: Price variables

\begin{tabular}{ll}
\hline$p_{i r}$ & Output price of good $i$ produced in region $r$ for domestic market \\
$p_{i r}^{X}$ & Output price of good $i$ produced in region $r$ for export market \\
$p_{i r}^{E}$ & Price of aggregate energy in sector $i$ and region $r$ \\
$p_{i r}^{M}$ & Import price aggregate for good $i$ imported to region $r$ \\
$p_{i r}^{A}$ & Price of Armington good $i$ in region $r$ \\
$p_{r}^{C}$ & Price of aggregate household consumption in region $r$ \\
$p_{C r}^{E}$ & Price of aggregate household energy consumption in region $r$ \\
$w_{r}$ & Wage rate in region $r$ \\
$v_{r}$ & Price of capital services in region $r$ \\
$q_{i r}$ & Rent to natural resources in region $r(\mathrm{i} \in \mathrm{FF})$ \\
$t_{r}^{C O 2}$ & $\mathrm{CO}_{2}$ tax in region $r$ \\
\hline
\end{tabular}


Table C.4: Endowments and emissions coefficients

\begin{tabular}{|c|c|}
\hline $\bar{L}_{r}$ & Aggregate labor endowment for region $r$ \\
\hline $\bar{K}_{r}$ & Aggregate capital endowment for region $r$ \\
\hline $\bar{Q}_{i r}$ & Endowment of natural resource $i$ for region $r(i \in F F)$ \\
\hline $\bar{B}_{r}$ & Balance of payment deficit or surplus in region $\mathrm{r}$ (note: $\sum_{r} \bar{B}_{r}=0$ ) \\
\hline$\overline{\mathrm{CO}_{2 r}}$ & Endowment of carbon emission rights in region $r$ \\
\hline$a_{i}^{C O_{2}}$ & Carbon emissions coefficient for fossil fuel $\mathrm{i}(\mathrm{i} \in \mathrm{FF}$ ) \\
\hline
\end{tabular}

Table C.5: Cost shares

\begin{tabular}{|c|c|}
\hline$\theta_{i r}^{X}$ & Share of exports in sector $i$ and region $r$ \\
\hline$\theta_{j i r}$ & Share of intermediate good $j$ in sector $i$ and region $r(\mathrm{i} \notin \mathrm{FF})$ \\
\hline$\theta_{i r}^{K L E}$ & Share of KLE aggregate in sector $i$ and region $r(\mathrm{i} \notin \mathrm{FF})$ \\
\hline$\theta_{i r}^{E}$ & Share of energy in the KLE aggregate of sector $i$ and region $r(\mathrm{i} \notin \mathrm{FF})$ \\
\hline$\alpha_{i r}^{T}$ & Share of labor $(T=L)$ or capital $(T=K)$ in sector $i$ and region $r(\mathrm{i} \notin \mathrm{FF})$ \\
\hline$\theta_{i r}^{Q}$ & Share of natural resources in sector $i$ of region $r(\mathrm{i} \in \mathrm{FF})$ \\
\hline$\theta_{T i r}^{F F}$ & Share of good $i(T=i)$ or labor $(T=L)$ or capital $(T=K)$ in sector $i$ and region $r(\mathrm{i} \in \mathrm{FF})$ \\
\hline$\theta_{i r}^{C O A}$ & Share of coal in fossil fuel demand by sector $i$ in region $r(\mathrm{i} \notin \mathrm{FF})$ \\
\hline$\theta_{i r}^{E L E}$ & Share of electricity in energy demand by sector $i$ in region $r$ \\
\hline$\beta_{j i r}$ & Share of liquid fossil fuel $j$ in energy demand by sector $i$ in region $r(\mathrm{i} \notin \mathrm{FF}, \mathrm{j} \in \mathrm{LQ}$ ) \\
\hline$\theta_{i s r}^{M}$ & Share of imports of good $i$ from region $s$ to region $r$ \\
\hline$\theta_{i r}^{A}$ & Share of domestic variety in Armington good $i$ of region $r$ \\
\hline$\theta_{C r}^{E}$ & Share of fossil fuel composite in aggregate household consumption in region $r$ \\
\hline$\gamma_{i r}$ & Share of non-energy good $i$ in non-energy household consumption demand in region $r$ \\
\hline$\theta_{i C r}^{E}$ & Share of fossil fuel $i$ in household energy consumption in region $r$ \\
\hline
\end{tabular}




\begin{tabular}{|c|c|c|}
\hline$\eta$ & $\begin{array}{l}\text { Transformation between production for the domestic market and } \\
\text { production for the export }\end{array}$ & 2 \\
\hline$\sigma_{K L E}$ & $\begin{array}{l}\text { Substitution between energy and value-added in production (except } \\
\text { fossil fuels) }\end{array}$ & 0.8 \\
\hline \multirow[t]{3}{*}{$\sigma_{Q, i}$} & \multirow{3}{*}{$\begin{array}{l}\text { Substitution between natural resources and other inputs in fossil fuel } \\
\text { production calibrated consistently to exogenous supply elasticities } \mu_{F F}\end{array}$} & $\mu_{\mathrm{COA}}=0.5$ \\
\hline & & $\mu_{\mathrm{CRU}}=1.0$ \\
\hline & & $\mu_{\mathrm{GAS}}=1.0$ \\
\hline$\sigma_{E L E}$ & $\begin{array}{l}\text { Substitution between electricity and the fossil fuel aggregate in } \\
\text { production }\end{array}$ & 0.3 \\
\hline$\sigma_{C O A}$ & $\begin{array}{l}\text { Substitution between coal and the liquid fossil fuel composite in } \\
\text { production }\end{array}$ & 0.5 \\
\hline$\sigma_{A}$ & Substitution between the import aggregate and the domestic input & 4 \\
\hline$\sigma_{M}$ & Substitution between imports from different regions & 8 \\
\hline$\sigma_{E C}$ & $\begin{array}{l}\text { Substitution between the fossil fuel composite and the non-fossil fuel } \\
\text { consumption aggregate in household consumption }\end{array}$ & 0.8 \\
\hline$\sigma_{F F, C}$ & $\begin{array}{l}\text { Substitution between fossil fuels in household fossil energy } \\
\text { consumption }\end{array}$ & 0.3 \\
\hline
\end{tabular}

For the sensitivity analysis reported in section 4, the lower and upper values of the uniform probability distributions for six key elasticities are as follows:

$1<\sigma_{A}<4 ; 2<\sigma_{M}<8 ; 0.25<\sigma_{K L E}<0.75 ; 0.6<\sigma_{C}<1 ; 0.25<\mu_{C R U}<1 ; 0.25<\mu_{C O L}<1$.

Figure C.1: Nesting in non-fossil fuel production

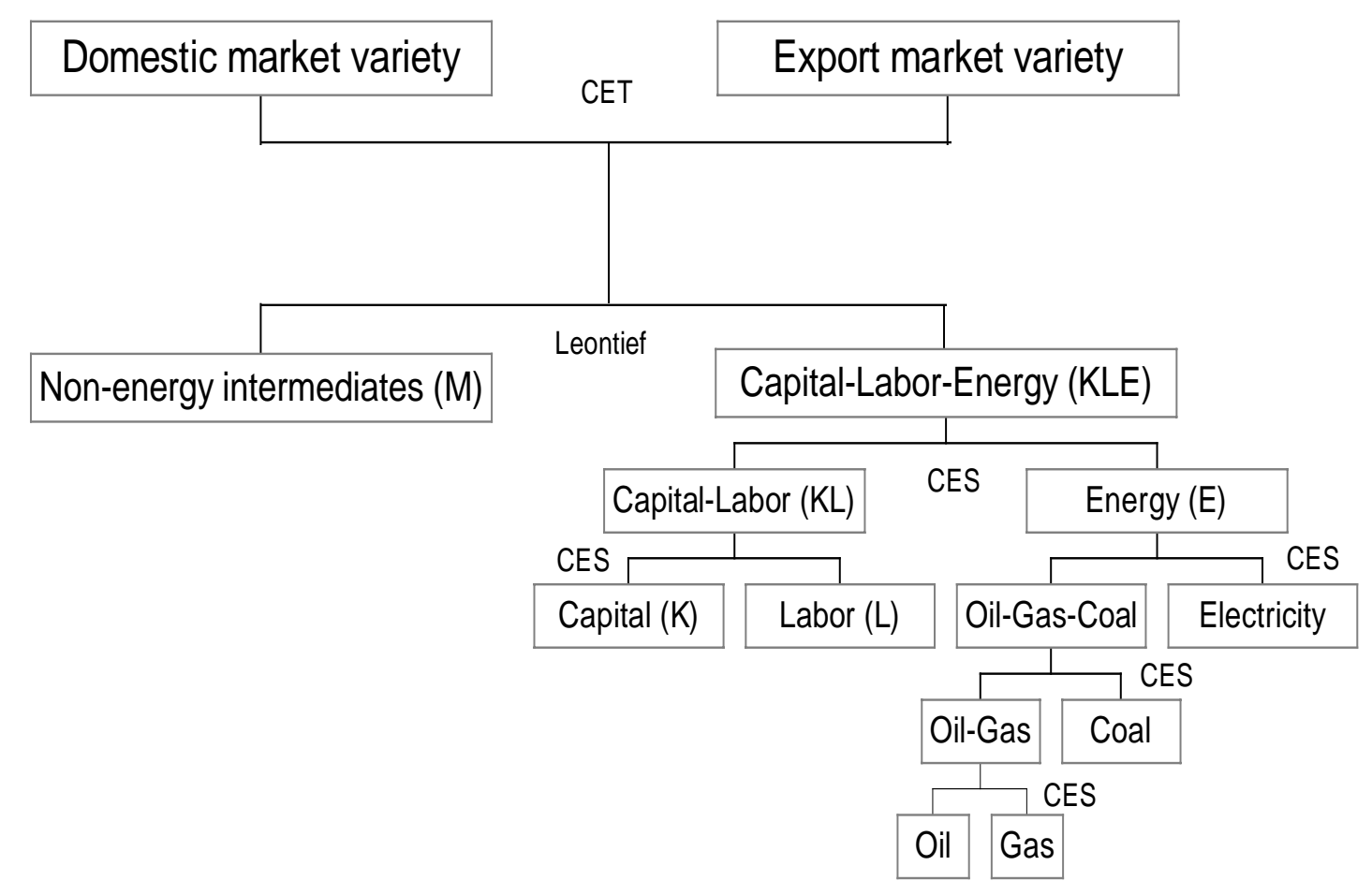


Figure C.2: Nesting in fossil fuel production

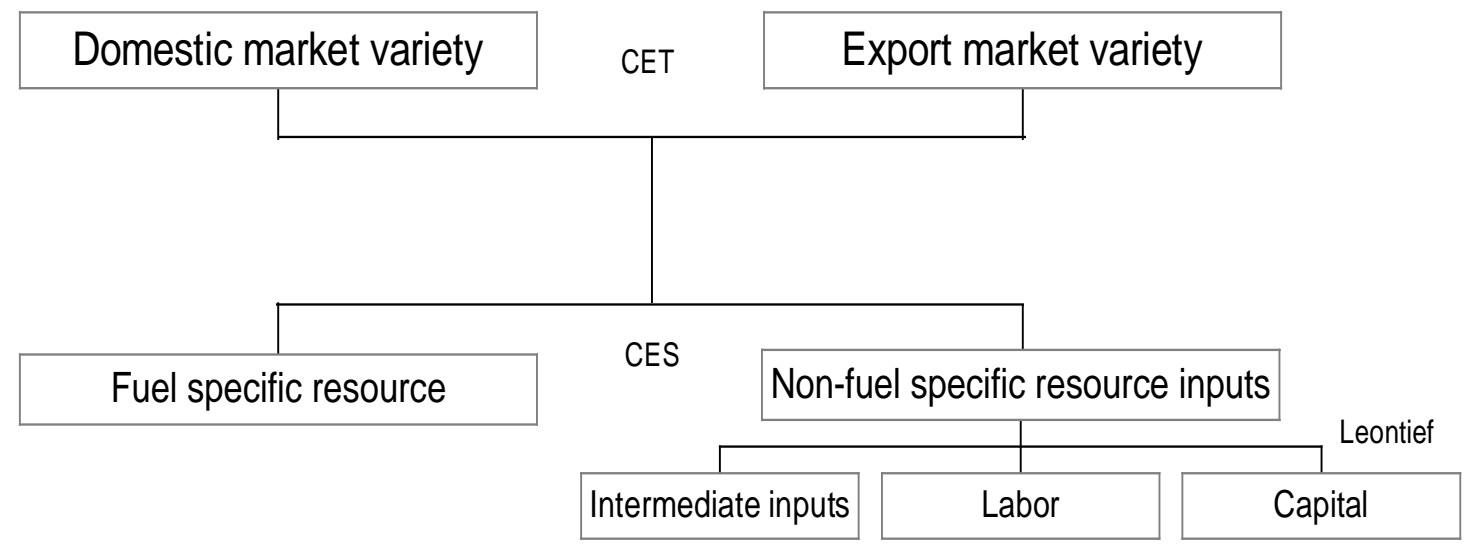

Figure C.3: Nesting in household consumption

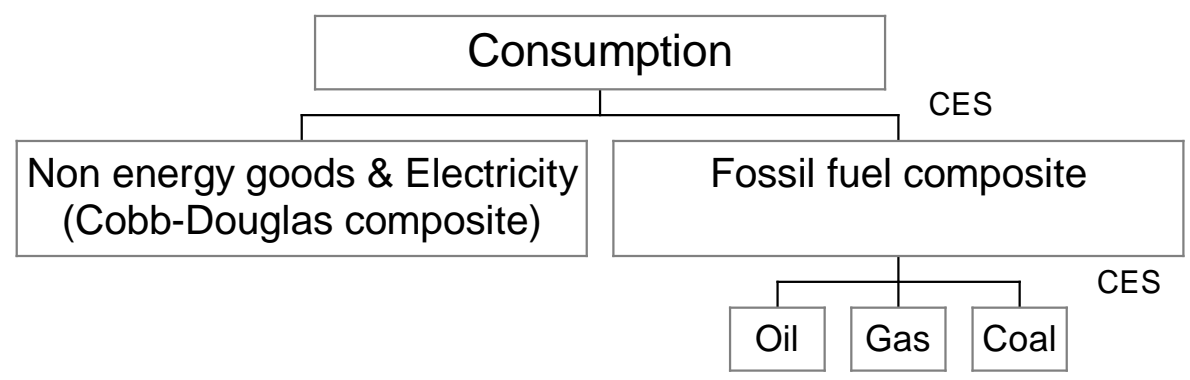

Figure C.4: Nesting in Armington production

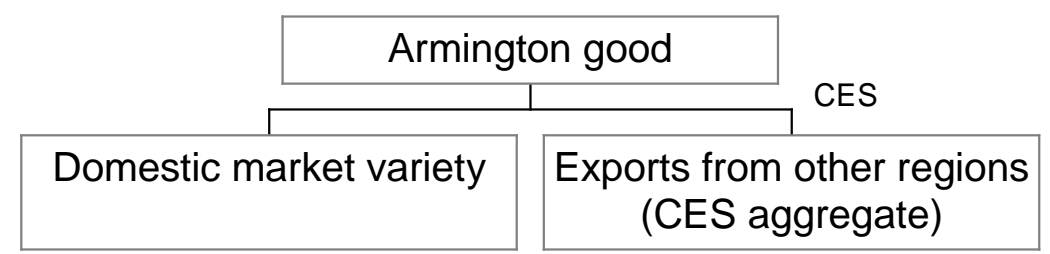

\section{Benchmark Data - Regional and Sectoral Aggregation}

The model is built on a comprehensive energy-economy dataset that accommodates a consistent representation of energy markets in physical units as well as detailed accounts of regional production and bilateral trade flow. The underlying data base is GTAP-EG which reconciles the most recent GTAP economic production and trade dataset for the year 1997 with OECD/IEA energy statistics for 50 regions and 23 sectors (Rutherford and Paltsev, 2000). Benchmark data determine parameters of the functional forms from a given set of benchmark quantities, prices, and elasticities. Sectors and regions of the original GTAP-EG 
data set are aggregated according to Tables C.7 and C.8 to yield the model's sectors and regions (see Table 3 ).

Table C.7: Sectoral aggregation

\begin{tabular}{|c|c|c|c|}
\hline \multicolumn{4}{|c|}{ Sectors in GTAP-EG } \\
\hline AGR & Agricultural products & NFM & Non-ferrous metals \\
\hline CNS & Construction & NMM & Non-metallic minerals \\
\hline COL & Coal & OIL & Refined oil products \\
\hline CRP & Chemical industry & OME & Other machinery \\
\hline CRU & Crude oil & $\mathrm{OMF}$ & Other manufacturing \\
\hline DWE & Dwellings & OMN & Mining \\
\hline ELE & Electricity and heat & PPP & Paper-pulp-print \\
\hline FPR & Food products & SER & Commercial and public services \\
\hline GAS & Natural gas works & $\mathrm{T}_{-} \mathrm{T}$ & Trade margins \\
\hline I_S & Iron and steel industry & TRN & Transport equipment \\
\hline LUM & Wood and wood-products & TWL & Textiles-wearing apparel-leather \\
\hline \multicolumn{4}{|c|}{ Mapping from aggregate model sectors to GTAP-EG sectors ${ }^{*}$} \\
\hline \multicolumn{4}{|c|}{ Energy } \\
\hline $\mathrm{COL}$ & Coal & \multicolumn{2}{|l|}{$\mathrm{COL}$} \\
\hline CRU & Crude oil & \multicolumn{2}{|l|}{ CRU } \\
\hline GAS & Natural gas & \multicolumn{2}{|l|}{ GAS } \\
\hline OIL & Refined oil products & \multicolumn{2}{|l|}{ OIL } \\
\hline ELE & Electricity & \multicolumn{2}{|l|}{ ELE } \\
\hline \multicolumn{4}{|c|}{ Non-Energy } \\
\hline EIS & Energy-intensive sectors & \multicolumn{2}{|c|}{ CRP, I_S, NFM, NMM, PPP, TRN } \\
\hline ROI & Rest of industry & \multicolumn{2}{|c|}{$\begin{array}{l}\text { AGR, CNS, DWE, FPR, LUM, OME, OMF, } \\
\text { OMN, SER, T_T, TWL }\end{array}$} \\
\hline \multicolumn{4}{|c|}{$\begin{array}{l}\text { Set } i \text { in Table C. } 1 \text { includes two additional artificial production sectors (CGD and G) that denote the } \\
\text { (exogenous) demand for an investment/savings good (CGD) and the public good (G). }\end{array}$} \\
\hline \multicolumn{4}{|c|}{ Table C.8: Regional aggregation } \\
\hline \multicolumn{4}{|c|}{ Regions in GTAP-EG } \\
\hline ARG & Argentina & MYS & Malaysia \\
\hline AUS & Australia & NZL & New Zealand \\
\hline BRA & Brazil & PHL & Philippines \\
\hline CAM & Central America \& Caribbean & RAP & Rest of Andean Pact \\
\hline CAN & Canada & RAS & Rest of South Asia \\
\hline CEA & Central European Associates & REU & Rest of EU \\
\hline CHL & Chile & $\mathrm{RME}$ & Rest of Middle East \\
\hline
\end{tabular}


Table C.8: $\quad$ continued

\begin{tabular}{llll}
\hline CHN & China & RNF & Rest of North Africa \\
COL & Columbia & ROW & Rest of World \\
DEU & Germany & RSA & Rest of South Africa \\
DNK & Denmark & RSM & Rest of South America \\
EFT & European Free Trade Area & RSS & Rest of South-Saharan Africa \\
FIN & Finland & SAF & South Africa \\
FSU & Former Soviet Union & SGP & Singapore \\
GBR & United Kingdom & SWE & Sweden \\
HKG & Hong Kong & THA & Thailand \\
IDN & Indonesia & TUR & Turkey \\
IND & India & TWN & Taiwan \\
JPN & Japan & URY & Uruguay \\
KOR & Republic of Korea & USA & United States of America \\
LKA & Sri Lanka & VEN & Venezuela \\
MAR & Morocco & VNM & Vietnam \\
MEX & Mexico & & \\
\hline
\end{tabular}

Mapping from aggregate model regions to GTAP-EG regions

Industrialized world

\begin{tabular}{lll} 
AUN & Australia, New Zealand & AUS, NZL \\
CAN & Canada & CAN \\
EUR & OECD Europe (incl. EFTA) and & CEA, DEU, DNK, EFT, FIN, GBR, REU, \\
& Central and Eastern Associates & SWE, TUR \\
FSU & Former Soviet Union & FSU \\
JPN & Japan & JPN \\
USA & United States & USA \\
& Developing world \\
AFR & MAR, RSA, RSS, SAF \\
ASI & KOR, LKA, PHL, RAS, ROW, SGP, THA, \\
& TWN, VNM \\
CHN & CHN \\
IND & IND \\
MPC & IDN, MEX, MYS, RME, RNF, VEN \\
MSA & ARG, BRA, CAM, CHL, COL, RAP, RSM \\
\hline
\end{tabular}

Baseline Projections - Forward Calibration

The magnitude and distribution of abatement costs associated with the implementation of the Kyoto emission constraints crucially depend on the $B a U$ projections for GDP, fuel prices, energy efficiency improvements, etc. In our comparative-static framework, we infer the $B a U$ 
economic structure of the model's regions for the year 2020 using most recent projections by the International Energy Outlook (DOE, 2001) for GDP growth, fossil fuel production, and future energy prices. We incorporate autonomous energy efficiency improvement factors which scale energy demand functions to match the exogenous emission forecasts. The concrete forward calibration of the model entails three steps.

First, we fix the time profile of fossil fuel supplies from the model's regions to the exogenous baseline projections by making supplies inelastic and scaling sector-specific resources with the exogenous growth rates in fossil fuel production. This allows us to partially control the emission profile from the supply side. Within the $B a U$ calculation, we endogenously adjust the resource endowments of fossil fuels to calibrate the model to given exogenous target prices for fossil fuels. At the same time we incorporate exogenous, regionspecific GDP growth rates to scale the labor and capital stock of our static model.

Second, we incorporate exogenous autonomous energy efficiency improvements to match the exogenous carbon emission profiles The autonomous energy efficiency improvement reflects the rate of change in energy intensity, i.e. the ratio of energy consumption over gross domestic product, holding energy prices constant. It is a measure of all non-price induced changes in gross energy intensity including technical developments that increase energy efficiency as well as structural changes.

Third, we recalibrate fossil fuel supply functions locally to exogenous estimates of supply elasticities. The last step assures empirical reaction of fossil fuel production to policy induced changes in world energy prices of fuels. 


\section{References}

Armington, P. S. (1969). A Theory of Demand for Products Distinguished by Place of Production. IMF Staff Papers 16: 159-178.

Brooke, A., D. Kendrick and A. Meeraus (1996), GAMS: A User's Guide, Washington DC: GAMS Development Corp.

Dirkse, S. and M. Ferris (1995), 'The PATH Solver: A Non-monotone Stabilization Scheme for Mixed Complementarity Problems', Optimization Methods and Software, 5, $123-156$.

DOE (Department of Energy) (2001), International Energy Outlook, Washington, DC: Energy Information Administration.

Gordon, T. J. and H. Hayward (1968), 'Initial Experiments with the Cross-Impact Matrix Method of Forecasting', Futures, 1 (2), 100-116.

Helmer, O. (1972), 'Cross-Impact Gaming', Futures, 4 (2), 149-167.

Honton, E. J., G. S. Stacey and S. M. Millett (1984), 'Futures Scenarios: The BASICS Computational Method', Battelle Columbus Division, Economics and Policy Analysis, Occasional Paper 44.

Mißler-Behr, M. (1993), Methoden der Szenarioanalyse, Wiesbaden: Deutscher UniversitätsVerlag.

McDougall, R. A., A. Elbehri and T. P. Truong (1998), Global Trade, Assistance and Protection: The GTAP 4 Data Base, West Lafayette: Center for Global Trade Analysis, Purdue University.

Rutherford, T. F. (1999), 'Applied General Equilibrium Modelling with MPSGE as a GAMS Subsystem: An Overview of the Modelling Framework and Syntax', Computational Economics, 14, 1-46.

Rutherford, T. F. and S. V. Paltsev (2000), GTAP-EG: Incorporating Energy Statistics into GTAP Format, University of Colorado Department of Economics. 